\title{
QUÍMICA MINERAL DE ANFIBÓLIOS E BIOTITAS E CONDIÇÕES DE CRISTALIZAÇÃO DE GRANITÓIDES PALEOPROTEROZÓICOS DA REGIÃO DE VILA RIOZINHO, PROVÍNCIA AURÍFERA DO TAPAJÓS, CRÁTON AMAZÔNICO
}

\author{
CLAUDIO NERY LAMARÃ ${ }^{1,2} \&$ ROBERTO DALL'AGNOL ${ }^{1,2}$
}

\begin{abstract}
The Old São Jorge, Younger São Jorge, Jardim do Ouro, porphyry granites, and the Maloquinha suite granitoids found in the Vila Riozinho region, eastern portion of the Tapajós Gold Province, are representative of the Paleoproterozoic magmatism (1.98$1.88 \mathrm{Ga}$ ). The quartz monzodioritic rocks of the Older São Jorge granite have amphiboles with $\mathrm{Mg}$-hastingsite, tschermakite and $\mathrm{Mg}$ hornblende composition. The dominant monzogranitic facies and the less frequent quartz syenitic rocks have homogeneous $\mathrm{Mg}$ hornblende with rare borders of actinolite. The high $\mathrm{Mg} /\left(\mathrm{Mg}+\mathrm{Fe}_{2}\right)$ ratios and the $\mathrm{Al}$ contents in amphibole indicate crystallization under oxidizing conditions at pressures between $3-1$ kbar for the monzogranitic facies and $<1.7 \mathrm{kbar}$ for the quartz-syenitic facies. The Younger São Jorge granite contains $\mathrm{Mg}$-hornblende and actinolite with slightly higher $\mathrm{Mg} /\left(\mathrm{Mg}+\mathrm{Fe}_{2}\right)$ ratios but with inferior $\mathrm{Al}$, content compared to equivalent rocks of the Older São Jorge granite. Al-in amphibole indicate crystallization between 2-1 kbar. The Jardim do Ouro granite amphibole varies from Fe-hornblende to Fe-edenite with comparatively lower $\mathrm{Mg} /\left(\mathrm{Mg}+\mathrm{Fe} \mathrm{e}_{2}\right)$ ratios, indicating crystallization in a somewhat less oxidizing setting. In the porphyry granite associated with Older São Jorge granite, an homogeneous $\mathrm{Mg}$-hornblende with $\mathrm{Mg} /(\mathrm{Mg}+\mathrm{Fe}$, $)$ ratios, alcalis and $\mathrm{Al}_{1}$ contents similar to the amphiboles of the monzogranitic rocks of that pluton predominate, suggesting that both rocks are cogenetic. A porphyry granite, associated with ignimbrites of the Moraes Almeida Formation and Maloquinha suite, contains Fe-hornblende similar in composition to the amphiboles of the Jardim do Ouro granite, indicating a possible relationship between these rocks. The biotite of the Older São Jorge granite, Younger São Jorge granite and porphyry granite associated with the former is a Mg-biotite with evidence of post-magmatic reequilibrium. The biotite of the Jardim do Ouro granite is comparatively enriched in iron and does not show evidence of post-magmatic reequilibrium.
\end{abstract}

Keywords: Amazonian Craton, granitoids, calc-alkaline, amphibole, biotite

Resumo Os granitos São Jorge Antigo, São Jorge Jovem, Jardim do Ouro, pórfiros e aqueles da Suíte Maloquinha são representativos do magmatismo paleoproterozóico $(1,98$ a 1,88 Ga) da região de Vila Riozinho, porção leste da Província Aurífera do Tapajós. No Granito São Jorge Antigo, as rochas quartzo-monzodioríticas possuem anfibólios de composição Mg-hastingsita, tschermakita e hornblenda magnesiana. Nas rochas monzograníticas, dominantes, e quartzo-sieníticas, pouco freqüentes, ocorre hornblenda magnesiana homogênea com raras bordas actinolíticas. As altas razões $\mathrm{Mg} /\left(\mathrm{Mg}+\mathrm{Fe}_{2}\right)$ e os conteúdos de $\mathrm{Al}_{1}$ desse anfibólio indicam formação em ambiente com elevada $f \mathrm{O}_{2}$, a pressões variáveis entre $3 \mathrm{e} 1 \mathrm{kbar}$ para a fácies monzogranítica e inferiores a $1,7 \mathrm{kbar}$ para a quartzosienítica. Pressões de $6 \pm 1$ kbar foram obtidas em Mg-hastingsita e tschermakita das rochas monzodioríticas. Entretanto, a composição da hornblenda magnesiana presente nas bordas de muitos cristais de anfibólio desta fácies sugere um final de colocação e cristalização a pressões similares àquelas das rochas monzograníticas. No Granito São Jorge Jovem, ocorrem hornblenda magnesiana e actinolita com razōes $\mathrm{Mg} /\left(\mathrm{Mg}+\mathrm{Fe}_{2}\right)$ um pouco mais elevadas do que as de rochas equivalentes do Granito São Jorge Antigo, porém com conteúdos de $\mathrm{Al}$ mais baixos, indicando cristalização entre $2 \mathrm{e} 1 \mathrm{kbar}$. A presença nesse granito de muitos anfibólios com composição actinolítica sugere a possibilidade de reequilíbrio subsolidus expressivo e tais valores devem ser tomados com precaução. O Granito Jardim do Ouro possui anfibólios com razões $\mathrm{Mg} /\left(\mathrm{Mg}+\mathrm{Fe}_{2}\right)$ mais baixas que variam de $\mathrm{Fe}$-edenita a Fe-hornblenda, indicando cristalização em ambiente comparativamente menos oxidante. Seus conteúdos de $\mathrm{Al}_{1}$ elevados sugerem cristalização a pressões entre 4,5 e 3 kbar. Porém, como esses anfibólios são mais ricos em ferro do que os dos demais granitóides e formaram-se em menor $f \mathrm{O}_{2}$, é possível que tal pressão esteja superestimada. No granito pórfiro associado ao Granito São Jorge Antigo ocorre hornblenda magnesiana bastante homogênea com razões $\mathrm{Mg} /\left(\mathrm{Mg}+\mathrm{Fe}_{2}\right)$, conteúdos de álcalis e $\mathrm{Al}_{1}$ similares ao do anfibólio das rochas monzograníticas deste corpo, sugerindo uma ligação genética entre essas rochas. Um granito pórfiro, associado aos ignimbritos da Formação Moraes Almeida e à Suíte Maloquinha, contém Fe-hornblenda de composição semelhante a dos anfibólios do Granito Jardim do Ouro, o que sugere uma possível ligação entre ambos. As biotitas dos granitos São Jorge Antigo, São Jorge Jovem e do granito pórfiro associado ao primeiro são magnesianas, similares às encontradas em granitos cálcico-alcalinos, e mostram reequilíbrio pós-magmático. A biotita do Granito Jardim do Ouro é ferrosa, situa-se no limite entre biotitas de granitos subalcalinos e alcalinos e não apresenta sinais de reequilíbrio pósmagmático.

Palavras-chave: Cráton Amazônico, granitóides, cálcico-alcalino, anfibólio, biotita.

INTRODUÇÃO Anfibólio, biotitae plagioclásio, minerais comuns em rochas ígneas intermediárias a ácidas, podem desenvolver um papel importante na petrogênese de rochas graníticas, sendo potencialmente úteis no estudo da natureza e das condições físicoquímicas dos magmas nos quais cristalizaram. Neste trabalho, são apresentados os dados de química mineral de anfibólio e biotita dos granitos São Jorge Antigo, São Jorge Jovem, Jardim do Ouro e pórfiros da região de Vila Riozinho, Província Aurífera do Tapajós, e discutidas as implicações dos mesmos em termos das tipologias destes granitóides, bem como das suas condições de formação.

1 - Grupo de Pesquisa Petrologia de Granitóides (GPPG) - Centro de Geociências - CG-UFPA

2 - Departamento de Geoquímica e Petrologia/CG - UFPA, Caixa Postal 1611. CEP-66075-900. E-mails: lamarao@ufpa.br, robdal@ufpa.br 
CONTEXTOGEOLÓGICODA PROVÍNCIA AURÍFERA DO TAPAJÓS A Província Aurífera do Tapajós (Faraco et al. 1997), localizada na porção central do Cráton Amazônico, abrange parte das províncias Ventuari-Tapajós (ou Tapajós-Parima, Santos et al. 2000) e Amazônia Central (Tassinari \& Macambira 1999), sendo caracterizada por um extenso magmatismo vulcano-plutônico Paleoproterozóico (Lamarão et al. 2002). O seu embasamento está representado por rochas metavulcano-sedimentares do Grupo Jacareacanga, com idades U-Pb em zircões detríticos de metaturbiditos em torno de $2.1 \mathrm{Ga}$ (Santos et al. 2000,2001), e por rochas granito-gnáissicas do Complexo Cuiú-Cuiú, com idade U$\mathrm{Pb}$ em zircão em rochas tonalíticas de $2015 \pm 9$ e $2033 \pm 7 \mathrm{MA}$ (Santos et al. 2001). As outras rochas plutônicas são enquadradas nas suítes Creporizão (Ricci et al. 1999), Parauarí e Maloquinha (Santos et al. 1975, Vasquez et al. 1999, Klein \& Vasquez 2000). As duas primeiras apresentam afinidade cálcico-alcalina (Vasquez et al. 2001) e formam extensos batólitos irregulares. A Suíte Creporizão é representada por sienogranitos e monzogranitos com granodioritos e tonalitos subordinados, geralmente deformados, com idades U-Pb e $\mathrm{Pb}-\mathrm{Pb}$ em zircão de $1997 \pm 3 \mathrm{Ma}$ a $1957 \pm 6 \mathrm{Ma}$ (Santos et al. 2001, Vasquez et al. 2000). A Suíte Parauarí é constituída dominantemente por monzogranitos e granodioritos, geralmente isentos de deformação, com idades em torno de 1,89 Ga (Brito et al. 1999, Vasquez et al. 1999, Santos et al. 2000). A Suíte Maloquinha, com características de granitos do tipo-A (Vasquez et al. 2001), é dominada por sienogranitos e álcali-feldspato-granitos com idades em torno de 1,88 Ga (Lamarão et al. 1999, 2002, Lamarão 2001, Vasquez et al. 1999, Santos et al. 2000).

As rochas vulcânicas possuem ampla distribuição na Província, sendo agrupadas indistintamente no Grupo Iriri do Supergrupo Uatumã (Dall’Agnol \& Silva 1991, Dall’Agnol et al. 1999a, Klein \& Vasquez 2000, Moura et al. 1999, Santos 1984, Santos et al. 2000, Vasquez et al. 1999) ou, mais localizadamente, na Formação Bom Jardim (Almeida et al. 2000). Entretanto, os estudos petrográficos, geoquímicos e geocronológicos efetuados na região de Vila Riozinho (Lamarão et al. 1999, 2002, Lamarão 2001), acusaram a existência de duas seqüências vulcânicas temporal e geoquimicamente distintas. A mais antiga, denominada de Formação Vila Riozinho, possui idades Pb-Pb em zircão em torno de 2,0 Ga e afinidade cálcico-alcalina (Lamarão et al. 2002). A mais nova, designada de Formação Moraes Almeida, apresenta idades próximas de 1.88 Ga e caráter alcalino (Lamarão et al. 2002).

Rochas máficas, pertencentes às suítes Ingarana e Cachoeira Seca e ao Diabásio Crepori (Quadros et al. 1999, Bahia \& Quadros 2000, Klein \& Vasquez 2000), além de diversas coberturas sedimentares (Santos et al. 1975, Bahia \& Quadros 2000, Klein \& Vasquez 2000), completam o quadro estratigráfico da província.

\section{GEOLOGIA E GEOCRONOLOGIA DA REGIÃO DE VILA} RIOZINHO A região de Vila Riozinho, situada na porção leste da Província Aurífera do Tapajós (PAT), abrange as localidades de Vila Riozinho, Moraes Almeida e Jardim do Ouro (Fig. 1). É cortada no sentido N-S pela rodovia Cuiabá-Santarém (BR-163) e E-W, na sua porção norte, pela rodovia Transgarimpeira. Os rios Jamanxim, Riozinho das Arraias e o igarapé São Jorge são os principais afluentes da área. É constituída por diferentes tipos de rochas vulcânicas e plutônicas, as quais foram agrupadas, com base em dados de campo, petrográficos, geoquímicos e geocronológicos (Lamarão et al. 1999, 2002, Lamarão 2001), nas seguintes unidades geológicas (Fig. 1):

Formação Vila Riozinho É a unidade mais antiga, sendo forma- da por rochas vulcânicas intermediárias a ácidas que afloram em áreas topograficamente arrasadas nos arredores de Vila Riozinho e ao longo dos rios Jamanxim e Riozinho das Arraias, contornando o corpo granitóide São Jorge. Está representada por andesitos basálticos, traquiandesitos basálticos, traquitos e riolitos de afinidade cálcico-alcalina. Datações $\mathrm{Pb}-\mathrm{Pb}$ em zircão em traquitos forneceram idades de $2000 \pm 4$ Ma e $1998 \pm 3 \mathrm{Ma}$ (Lamarão et al. 2002).

Corpo Granitóide São Jorge É formado por dois granitos distintos (Lamarão \& Dall'Agnol 2002). O mais velho, denominado de Granito São Jorge Antigo, corresponde a um batólito irregular, com sinais locais de deformação intramagmática, que aflora nos arredores e a sul de Vila Riozinho e ao longo do Rio Jamanxim. Nas bordas nordeste, noroeste e oeste afloram rochas dioríticas a quartzo-dioríticas, enquanto mais para o centro e constituindo a fácies dominante ocorrem rochas monzograníticas. Na sua parte central, contornando uma área intensamente fraturada e hidrotermalizada onde está localizado o depósito de ouro São Jorge, pequenas serras de leucogranitos se destacam na topografia. Texturas rapakivi localizadas, enclaves $(5 \mathrm{a} 10 \mathrm{~cm})$ microgranulares escuros e diques de aplito rosados são feições comuns. Idades $\mathrm{Pb}-\mathrm{Pb}$ em zircão de $1981 \pm 2$ Ma e $1983 \pm 8$ Ma foram obtidas, respectivamente, em anfibólio-biotita-monzogranito e biotita-leucomonzogranito (Lamarão et al. 2002). O mais novo, denominado de Granito São Jorge Jovem, foi identificado inicialmente através de furos de sondagem na área mineralizada do depósito São Jorge, mas aflora também ao sul do granito São Jorge Antigo (Fig. 1). As ocorrências de texturas rapakivi localizadas, enclaves $(<5 \mathrm{~cm})$ microgranulares subarredondados e diques de aplito rosados são também comumente observadas. Datação $\mathrm{Pb}-\mathrm{Pb}$ em zircão em anfibólio-biotita-monzogranito da área mineralizada forneceu idade de 1891 \pm 3 Ma para este corpo (Lamarão et al. 2002).

Granito Jardim do Ouro Aflora na porção noroeste da área, às margens do rio Jamanxim, em um domínio morfologicamente arrasado. Apenas uma pequena parte da porção noroeste deste corpo foi estudada. Neste local, mostra-se isento de deformações e/ou transformações hidrotermais intensas. Apresenta coloração rosaacinzentada e fenocristais centimétricos $(<5 \mathrm{~cm})$ de álcali-feldspato rosado. Datação $\mathrm{Pb}-\mathrm{Pb}$ em zircão revelou idade de $1880 \pm 3 \mathrm{Ma}$ para este granito (Lamarão et al. 2002).

Formação Moraes Almeida É representada por vulcânicas ácidas isotrópicas que afloram nos arredores de Moraes Almeida. Predominam ignimbritos fortemente soldados e oxidados, ricos em cristais e fragmentos de cristais e líticos. A noroeste de Moraes Almeida ocorrem derrames de composição riolítica de coloração acinzentada. As relações de contato entre ignimbritos e riolitos não são visíveis no campo, porém os dados petrográficos, geoquímicos e geocronológicos (Lamarão 2001, Lamarão et al. 2002) sugerem que essas rochas estão relacionadas a um mesmo evento vulcânico. Na porção norte de Moraes Almeida, foram identificadas pequenas ocorrências de rochas vulcânicas traquíticas, mineralógica e composicionalmente diferentes das vulcânicas ácidas associadas. Datações $\mathrm{Pb}-\mathrm{Pb}$ em zircão revelaram idades de $1890 \pm 6$ Ma para os riolitos, $1881 \pm 4$ Ma para os traquitos e $1875 \pm 4$ Ma para os ignimbritos (Lamarão et al. 2002).

Suíte Maloquinha Ocorre dominantemente na porção norte da área na forma de morrotes abaulados e pequenas serras alongadas que envolvem as vulcânicas ácidas da Formação Moraes Almeida, 
sugerindo uma estrutura em caldeira (Fig. 1). É formada por leucogranitos isotrópicos, avermelhados, com idade $\mathrm{Pb}-\mathrm{Pb}$ em zircão de $1880 \pm 9 \mathrm{Ma}$ (Lamarão et al. 2002).

Granitos Pórfiros Várias ocorrências de granitos pórfiros foram identificadas na região de Vila Riozinho. Diversos deles associam- se ao Granito São Jorge Antigo (amostras 25c, 59, 67c; Fig. 1) e outros afloram no contato entre os ignimbritos e a Suíte Maloquinha (amostra 18a; Fig. 1). Ambos são monzograníticos, acinzentados e constituídos por fenocristais de plagioclásio esbranquiçado a levemente esverdeado, álcali-feldspato, quartzo e opacos

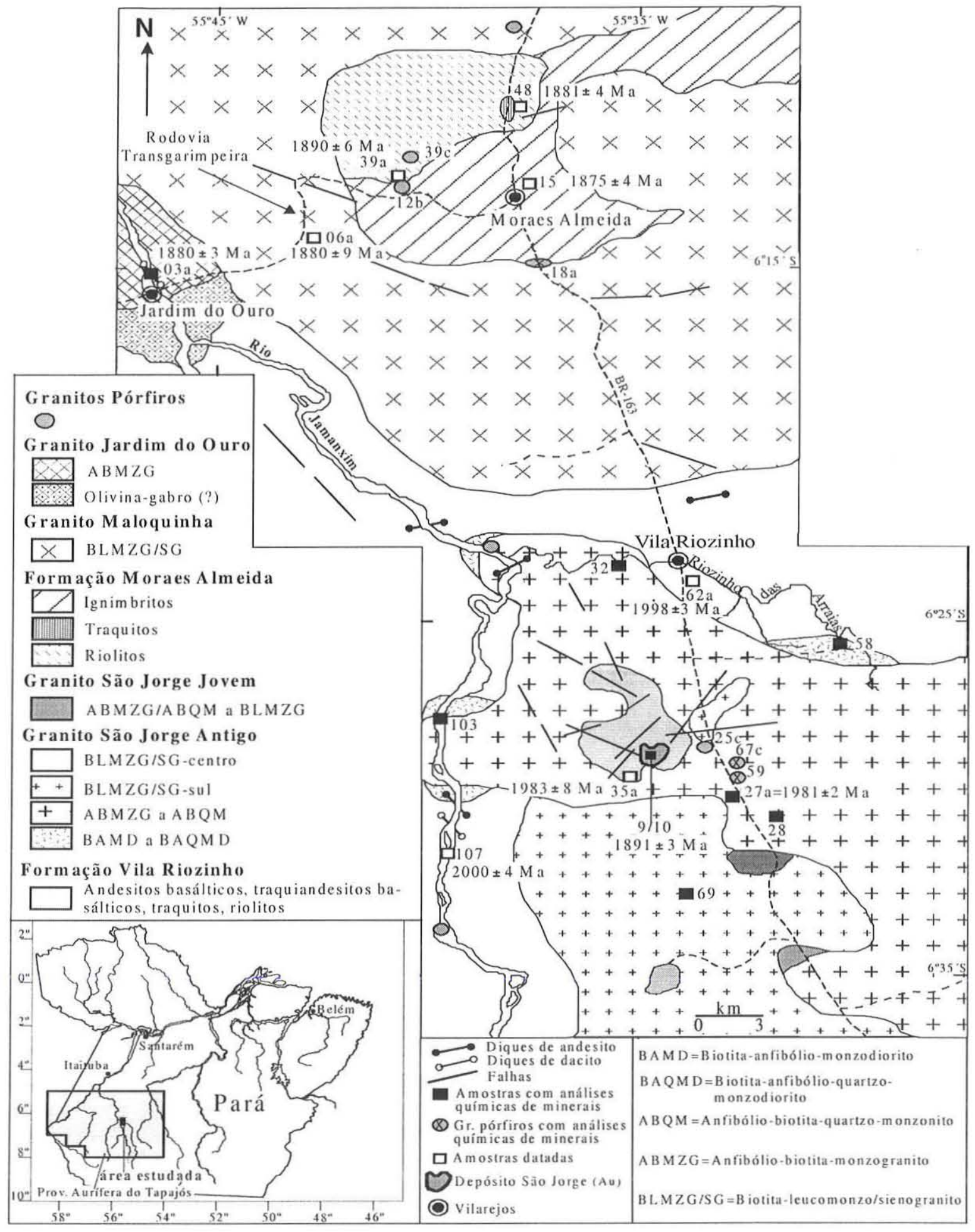

Figura I - Mapa geológico da região de Vila Riozinho mostrando a distribuição das diferentes unidades magmáticas identificadas e suas respectivas idades de formação (Lamarão et al. 2002). 
dispersos numa matriz fina, cinza-escura a cinza-avermelhada. Há ainda granitos pórfiros associados aos riolitos de Moraes Almeida (amostras 12b, 39c; Fig. 1), os quais são comparativamente mais pobres em minerais máficos e formados dominantemente por fenocristais de álcali-feldspato avermelhados, quartzo e plagioclásio imersos em matriz avermelhada. As características geoquímicas das associações vulcânicas e dos diferentes granitóides de Vila Riozinho são discutidas por Lamarão et al. (2002) e Lamarão \& Dall'Agnol (2002).

\section{PETROGRAFIA DASROCHASGRANITÓIDES GranitoSão}

Jorge Antigo É formado por uma série expandida que varia de biotita-anfibólio-monzodiorito a quartzo-monzodiorito (BAMD a BAQMD), anfibólio-biotita-monzogranito a quartzo-monzonito (ABMZG a ABQM), anfibólio-biotita-quartzo-sienito (ABQS) e biotita-leucomonzo/sienogranito (BLMZG/SG). A distribuição espacial dessas fácies sugere que o corpo é composicionalmente zonado (Fig. 1).

Os BAMD a BAQMD afloram nas bordas nordeste, noroeste e oeste e correspondem a fácies menos evoluída do corpo. São formados dominantemente por plagioclásio $\left(\mathrm{An}_{43-29}\right)$ e anfibólio, com quartzo, álcali-feldspato e biotita subordinados. Apatita, zircão, opacos e titanita são os principais acessórios primários. A fácies dominante é representada pelos ABMZG a ABQM. Possuem textura granular hipidiomórfica e são constituídos por anfibólio alterado em diferentes intensidades para biotita+titanita+ epidoto+sericita \pm carbonatos, plagioclásio saussuritizado $\left(\mathrm{An}_{29}\right.$. $\left.{ }_{18}\right)$, biotita, álcali-feldspato e quartzo. Os minerais acessórios primários são apatita, zircão, opacos e titanita e, os de origem secundária, sericita, clorita, , titanita e biotita. Rochas quartzosieníticas (ABQS) de granulação média e textura granular hipidiomórfica aparecem localmente. Os BLMZG/SG ocorrem nas porções sul e central do GSJA. As rochas da porção sul possuem textura granular hipidiomórfica média, localizadamente fina, e são formadas dominantemente por álcali-feldspato, quartzo e plagioclásio $\left(\mathrm{An}_{143.3}\right)$, com biotita subordinada. Pseudomorfos de anfibólio são raros. Possuem os mesmos acessórios das fácies anteriores, porém em menores proporções. Clorita, sericita, biotita, titanita, muscovita, albita e fluorita são os principais minerais secundários. Os BLMZG/SG da porção central, considerados a fácies mais evoluída do corpo (Lamarão \& Dall'Agnol 2002), não possuem pseudomorfos de anfibólio e são mais pobres em biotita.

Granito São Jorge Jovem É formado por anfibólio-biotitamonzogranito a quartzo-monzonito (ABMZG a ABQM) e biotitaleucomonzogranito(BLMZG) mineralógica e texturalmente similares a rochas equivalentes do Granito São Jorge Antigo.

Granito Jardim do Ouro É um anfibólio-biotita-monzogranito porfirítico, com cristais de plagioclásio zonados e sericitizados $\left(\mathrm{An}_{32-21}\right)$, quartzo intersticial fino a médio e fenocristais pertíticos de álcali-feldspato. A biotita, com até $4 \%$ modal, está geralmente alterada para clorita, opacos e titanita. $\mathrm{O}$ anfibólio ocorre em cristais subédricos finos a médios pouco alterados. Zircão, apatita, opacos, titanita e allanita são os acessórios primários. Clorita, sericita, titanita, biotita e, mais raramente, epidoto e fluorita são minerais secundários.

Suíte Maloquinha Predominam sienogranitos, com textura granular média a grossa, constituídos por álcali-feldspato argilizado, quartzo anédrico e plagioclásio sericitizado $\left(\mathrm{An}_{26-8}\right)$. O principal ferromagnesiano é a biotita tardia, geralmente alterada para clorita, titanita, muscovita e opacos.

Granitos Pórfiros Os granitos pórfiros associados ao Granito São Jorge Antigo e aqueles aflorantes no contato entre os ignimbritos e a Suíte Maloquinha (Fig. 1) são formados por cristais de quartzo freqüentemente subarredondados e com baías, plagioclásio zonado e alterado $\left(\mathrm{An}_{46-26}\right)$, álcali-feldspato, biotita e anfibólio dispersos numa matriz felsítica, por vezes granofírica. Zircão, apatita, titanita e opacos são os principais acessórios primários.

QUÍMICA MINERAL Anfibólios e biotitas foram analisados no Laboratório de Microssonda Eletrônica do Instituto de Geociências da UFRGS por meio de uma microssonda eletrônica do tipo CAMECA SX-50, sob as seguintes condições operacionais: tempo de aceleração de $15 \mathrm{kv}$; tempo de análise de $30 \mathrm{~s}$ para F, Mg, Al, $\mathrm{Na}$, $\mathrm{Si}$ e Sre de 20 s para Cl, K, Ca, Mn, Ti e Fe; corrente elétrica de 10 $\mathrm{nA}$; tamanho dos feixes de elétrons de 1 micron para biotitas e de 5 microns para anfibólios. As fórmulas estruturais dos anfibólios foram calculadas na base de 23 átomos de oxigênio utilizando-se o esquema de normalização 13 e CNK ( $\Sigma$ de cátions $=13$, excluindose $\mathrm{Ca}, \mathrm{Na}$ e K). Todos os anfibólios estudados possuem $(\mathrm{Ca}+\mathrm{Na})_{\mathrm{B}}$ $>1$ e $\mathrm{Na}_{\mathrm{B}}<0,5$ e pertencem ao grupo dos anfibólios cálcicos (Leake et al. 1997). As fórmulas estruturais das biotitas foram calculadas a 22 átomos de oxigênio, assumindo-se todo o ferro presente como $\mathrm{Fe}^{2+}$ (cf. Dymek 1983). A somatória do sítio octaédrico é maior que 5,5 , confirmando a natureza trioctaédrica dessas micas (Deer et al. 1992). O software MINPET, versão 2.02 (Richard 1995), foi utilizado para obtenção das fórmulas estruturais dos referidos minerais.

Anfibólio GRANITO SÃO JORGEANTIGO Nos BAQMD, o anfibólio representa a fase máfica dominante com até $20 \%$ modal (Lamarão 2001). Forma cristais euédricos a subédricos, com pleocroísmo marrom a marrom-claro no centro e verde claro nas bordas. Composicionalmente são formados por $\mathrm{Mg}$-hastingsita, tschermakita e hornblenda magnesiana (Fig. 2A, B). A Mghastingsita representa a fase mais precoce de cristalização. Possue razões $\mathrm{Mg} /\left(\mathrm{Mg}+\mathrm{Fe}_{2}\right)$ entre 0,79 e 0,77 e conteúdos de $\mathrm{Al}$ de 1,9 a 1,7 , o que sugere cristalização a pressões elevadas (Hammarstron \&Zen 1986, Hollister et al. 1987, Schmidt 1992, Anderson \& Smith 1995). A tschermakita tem razões $\mathrm{Mg} /\left(\mathrm{Mg}+\mathrm{Fe}_{2}\right)$ entre 0,79 e 0,71 e $\mathrm{Al}_{\mathrm{t}}$ entre 1,83 e 1,72 (Tabela 1). A hornblenda magnesiana mostra razões $\mathrm{Mg} /\left(\mathrm{Mg}+\mathrm{Fe}_{2}\right)$ próxima das anteriores, porém seus conteúdos de álcalis e $\mathrm{Al}_{1}$ são comparativamente mais baixos (Tabela 1).

Nas rochas quartzo-sieníticas domina hornblenda magnesiana (Fig. 2A) com razões $\mathrm{Mg} /\left(\mathrm{Mg}+\mathrm{Fe}_{2}\right)$ de 0,78 a 0,72 . O Al, entre 1,0 e 0,93 , se superpõe aos valores encontrados no anfibólio das rochas monzograníticas e sugere cristalização a pressões similares.

GRANITO SÃO JORGE JOVEM Ocorrem cristais subédricos a anédricos finos a médios, com pleocroísmo verde-claro a verdeamarelado. Somente cristais isentos ou com pouca alteração hidrotermal foram analisados. Mostram uma gradação composicional de hornblenda magnesiana para actinolita com o aumento de $\mathrm{Si}$ (Tabela 1; Fig. 2A). Raros cristais, entretanto, apresentam núcleos de composição actinolítica e bordas de hornblenda magnesiana, o inverso do que se deve esperar de um zoneamento magmático. Tal feição pode estar relacionada a reequilíbrio da hornblenda magnesiana primária na área do depósito São Jorge (cf. Chivas 


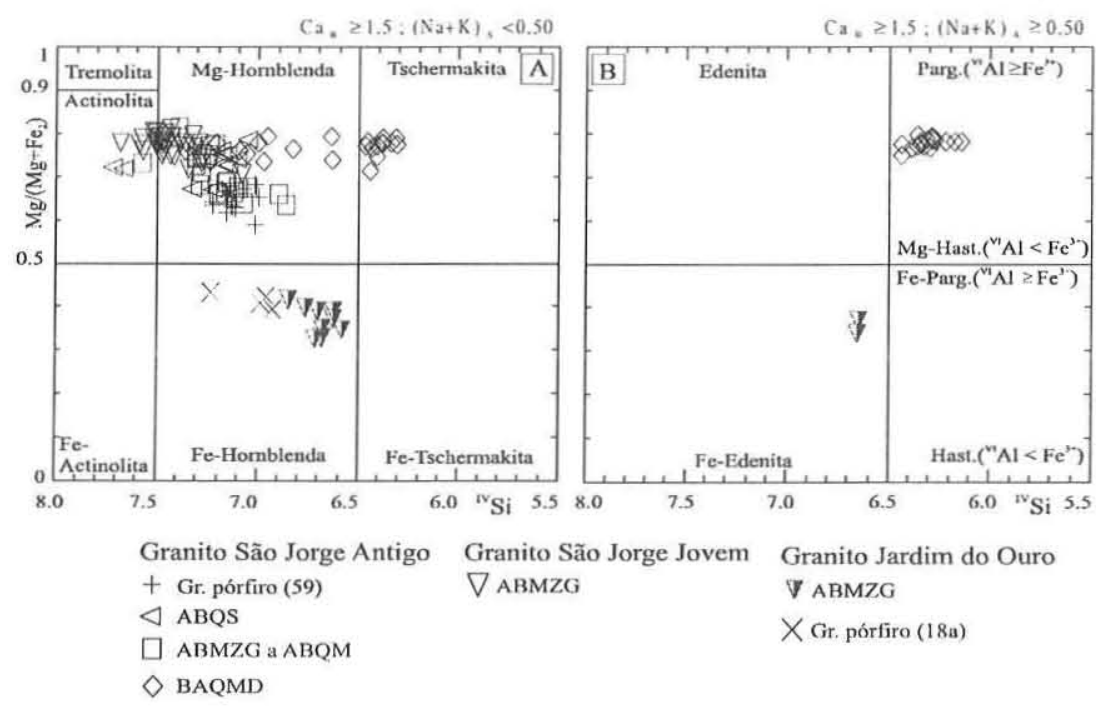

Figura 2 - (A, B) Diagramas de classificação de anfibólios (Leake et al. 1997) dos granitóides da região de Vila Riozinho. Siglas ds fácies como na figura 1, exceto ABas = anfibólio-biotita-quartzo-sienito.

1981). As razões $\mathrm{Mg} /(\mathrm{Mg}+\mathrm{Fe}$, $)$ relativamente elevadas e os baixos conteúdos de $\mathrm{Al}$ desses anfibólios (dominantemente $<1,0$; Tab. 1) sugerem cristalização em ambiente oxidante e a baixas pressões (Wones 1989, Anderson \& Smith 1995).

GRANITO JARDIM DO OURO Possui anfibólios subédricos a anédricos, médios a finos, com pleocroísmo verde-escuro a castanho-claro. Variam de ferro-edenita a ferro-hornblenda (Fig. $2 \mathrm{~A}$, B) com baixas razões $\mathrm{Mg} /\left(\mathrm{Mg}+\mathrm{Fe}_{2}\right)$ e teores moderados de $\mathrm{Al}_{t}$ $(0,39$ a 0,33 e 1,55 a 1,43, respectivamente; Tabela 1$)$.

GRANITOS PÓRFIROS Dentre os granitos pórfiros associados ao Granito São Jorge Antigo, selecionou-se a amostra 59 (Fig. 1). Os cristais de anfibólio são subédricos a anédricos, localizadamente euédricos, alterados em diferentes intensidades para biotita, titanita, clorita e epídoto. Correspondem a hornblenda magnesiana (Fig. 2A) com razões $\mathrm{Mg} /\left(\mathrm{Mg}+\mathrm{Fe}_{2}\right)$, conteúdos de álcalis e $\mathrm{Al}_{\text {t similares }}$ aos do anfibólio das rochas monzograníticas do Granito São Jorge Antigo (amostras 27 e 28), indicando que, além da associação espacial, há provavelmente uma ligação genética entre essas rochas.

O granito pórfiro associado aos ignimbritos e às rochas da Suíte Maloquinha (amostra 18a, Fig. 1), contém anfibólio subédrico a anédrico, fino a médio, com pleocroísmo castanho-esverdeado a verde-claro, alterado parcialmente para epídoto, biotita, titanita e clorita. Composicionalmente assemelha-se à ferro-hornblenda do Granito Jardim do Ouro (Fig. 2A), o que sugere a similaridade composicional de ambos magmas.

PRINCIPAIS SUBSTITUIÇÕES IDENTIFICADAS NOS ANFIBÓLIOS ESTUDADOS A análise de diagramas envolvendo relações catiônicas permitiu identificar os principais tipos de substituições que ocorreram nos anfibólios das rochas granitóides estudadas.

$\mathrm{Na}$ figura $3 \mathrm{~A}$, a forte correlação positiva entre ${ }^{\mathrm{IV}} \mathrm{Al}$ e álcalis confirma a importância da substituição edenítica $\left(\square_{A}+\mathrm{Si}={ }^{\mathrm{IV}} \mathrm{Al}+\right.$ $\mathrm{Na}_{A} ; \square=$ vacância) nos anfibólios dos diferentes granitóides. O diagrama Six ${ }^{\mathrm{IV}} \mathrm{Al}+(\mathrm{Na}+\mathrm{K})_{\mathrm{A}}$ (Anderson \& Smith 1995) mostra de modo mais claro esta substituição (Fig. 3B).

Outro tipo de substituição importante é a tschermakítica ( $\mathrm{Si}+$ $\mathrm{R}^{2}{ }_{\mathrm{Ml}-\mathrm{M} 3}={ }^{\mathrm{V}} \mathrm{Al}+{ }^{\mathrm{VI}} \mathrm{Al}$; Fig. 3C), responsável pela incorporação de ${ }^{\mathrm{V}} \mathrm{Al}$ em substituição a cátions divalentes nos sítios M1-M3 (Czamanske \& Wones 1973, Vyhnal et al. 1991).

A forte correlação linear mostrada no diagrama ${ }^{\mathrm{Vl}} \mathrm{Al}+\mathrm{Si} \mathrm{x}{ }^{\mathrm{V} / \mathrm{Ti}}+$ ${ }^{\mathrm{Iv}} \mathrm{Al}$ (Fig. 3D) sugere que ocorreram substituições entre Al e Ti no sítio octaédrico e evidencia a participação do Ti nas substituições que comandaram a evolução do anfibólio desses granitos.

Biotita A biotita do Granito São Jorge Antigo apresenta razões $\mathrm{Mg} /(\mathrm{Mg}+\mathrm{Fe})$ entre 0,63 e 0,53 e teores de $\mathrm{Al}_{t}$ decrescentes no sentido das rochas mais evoluídas (Tabela 2). É classificada como biotita magnesiana (Fig. 4A). O granito pórfiro associado a esse corpo (amostra 67c, Fig 1), possui biotita com razões $\mathrm{Mg} /(\mathrm{Mg}+\mathrm{Fe}$ ) constantes e comparativamente mais baixas $(0,45)$. Plota no campo de biotitas ferrosas, porém próximo ao campo de biotitas magnesianas (Fig. 4A).

A biotita do Granito São Jorge Jovem assemelha-se à biotita das rochas monzograníticas e monzoníticas do Granito São Jorge Antigo, sendo porém levemente mais enriquecida em $\mathrm{Mg}$ e mais pobre em Mn (Fig. 4A; Tabela 2).

O Granito Jardim do Ouro possui biotita que difere composicionalmente das demais. Apresenta as mais baixas razões $\mathrm{Mg} /(\mathrm{Mg}+\mathrm{Fe})$ e é mais rica em Fe e Ti e mais pobre em $\mathrm{Mg}$ e ${ }^{\mathrm{Vl}} \mathrm{Al}$, podendo ser classificada como biotita ferrosa (Fig. 4A; Tabela 2).

No diagrama ${ }^{\mathrm{IV}} \mathrm{Al} \times \mathrm{Fe} /(\mathrm{Fe}+\mathrm{Mg})$, as biotitas estudadas mostram trends paralelos caracterizados por variações limitadas nas razões $\mathrm{Fe} / \mathrm{Fe}+\mathrm{Mg}$ (Fig. 4B). O primeiro, formado pelas biotitas dos granitos São Jorge Antigo e São Jorge Jovem, mostra maior variação nos teores de ${ }^{\mathrm{IV}} \mathrm{Al}$, é mais pobre em ferro e se aproxima mais do polo flogopita. O segundo, representado pela biotita do Granito Jardim do Ouro, é mais rico em ferro, se deslocando em direção ao polo da anita. $\mathrm{O}$ terceiro, pertencente à biotita do granito pórfiro $(67 \mathrm{c})$, ocupa uma posição intermediária, porém mais próxima das biotitas dos granitos São Jorge Antigo e São Jorge Jovem. 
Tabela 1 - Análises de microssonda representativas de anfibólios dos granitóides da região de Vila Riozinho (Lamarão 2001).

\begin{tabular}{|c|c|c|c|c|c|c|c|c|c|c|c|c|c|c|c|c|}
\hline \multirow[b]{3}{*}{ Análise } & \multicolumn{6}{|c|}{ Granito São Jorge Antigo } & \multirow{2}{*}{\multicolumn{2}{|c|}{$\begin{array}{l}\text { Granito pórfiro } \\
\text { Amostra } 59 \\
\end{array}$}} & \multirow{2}{*}{\multicolumn{4}{|c|}{$\begin{array}{c}\begin{array}{c}\text { Granito São Jorge } \\
\text { Jovem }\end{array} \\
\text { ABMZG } \\
\end{array}$}} & \multirow{2}{*}{\multicolumn{2}{|c|}{$\begin{array}{c}\begin{array}{c}\text { Granito Jardim do } \\
\text { Ouro }\end{array} \\
\text { BMZG }\end{array}$}} & \multirow{2}{*}{\multicolumn{2}{|c|}{$\begin{array}{l}\text { Granbito pórfiro } \\
\text { amostra 18a }\end{array}$}} \\
\hline & \multicolumn{3}{|c|}{ BAQMD } & \multicolumn{2}{|c|}{$\mathrm{ABMZG}$ a $\mathrm{ABQM}$} & \multirow{2}{*}{$\frac{\mathrm{ABQS}}{\mathrm{S} 1 \mathrm{P} 101}$} & & & & & & & & & & \\
\hline & S1P5 & SIP3 & S9P27 & S2P115 & S7P79 & & S4P248 & S4P249 & S2P65 & S4P132 & S2P63 & S2P66 & S1P172 & S3P175 & S4P260 & S4P262 \\
\hline Tipo & MgHst & Tsch & $\mathrm{HbMg}$ & $\mathrm{HbMg}$ & $\mathrm{HbMg}$ & $\mathrm{HbMg}$ & $\mathrm{HbMg}$ & $\mathrm{HbMg}$ & $\mathrm{HbMg}$ & $\mathrm{HbMg}$ & $\mathrm{HbMg}$ & Act & $\mathrm{Fe}-\mathrm{Hb}$ & $\mathrm{Fe}-\mathrm{Hb}$ & $\mathrm{Fe}-\mathrm{Hb}$ & $\mathrm{Fe}-\mathrm{Hb}$ \\
\hline $\mathrm{SiO}_{2}$ & 43,846 & 43,079 & 45,257 & 46,506 & 50,421 & 48,615 & 48,157 & 48,871 & 48,348 & 50,904 & 51,829 & $\overline{52,911}$ & 42,462 & $\overline{43,341}$ & 45,659 & 47,917 \\
\hline $\mathrm{TiO}_{2}$ & 2,920 & 3,674 & 2,166 & 0.346 & 0,588 & 1,373 & 1,240 & 0,170 & 1,275 & 0,629 & 0,726 & 0,475 & 1,856 & 1,291 & 0,798 & 0,474 \\
\hline $\mathrm{Al}_{2} \mathrm{O}_{3}$ & 10,509 & 10,613 & 9,111 & 7,791 & 5,033 & 5,467 & 6,528 & 6,091 & 6,169 & 4,572 & 4,063 & 3,626 & 8,489 & 7,864 & 6,318 & 4,815 \\
\hline $\mathrm{MgO}$ & 14,073 & 14,187 & 13,334 & 11,131 & 13,693 & 14,038 & 13,026 & 12,121 & 13,600 & 15,263 & 15,620 & 15,767 & 5,863 & 5,698 & 7,369 & 7,962 \\
\hline $\mathrm{CaO}$ & 11,633 & 11,284 & 11,451 & 11,717 & 11,785 & 10,848 & 11,671 & 11,889 & 11,671 & 11,608 & 11,944 & 11,901 & 10,585 & 10,715 & 10,642 & 10,877 \\
\hline $\mathrm{MnO}$ & 0,248 & 0,179 & 0,517 & 1,123 & 1,004 & 0,783 & 0,613 & 0,666 & 0,573 & 0,501 & 0,552 & 0,524 & 0,919 & 0,946 & 0,965 & 1,131 \\
\hline $\mathrm{FeO}$ & 11,494 & 10,814 & 12,931 & 17,447 & 14,330 & 12,966 & 14,993 & 16,677 & 13,692 & 12,434 & 11,565 & 12,116 & 24,435 & 25,162 & 23,615 & 23,105 \\
\hline $\mathrm{Na}_{2} \mathrm{O}$ & 1,794 & 1,851 & 1,370 & 0,908 & 0,679 & 1,294 & 1,006 & 0,729 & 0,915 & 1,007 & 0,975 & 0,587 & 1,554 & 1,544 & 1,264 & 1,124 \\
\hline $\mathrm{K}_{2} \mathrm{O}$ & 0,961 & 0,916 & 0,804 & 0,678 & 0,473 & 0,743 & 0,786 & 0,532 & 0,752 & 0,469 & 0,375 & 0,335 & 1,200 & 1,272 & 0,911 & 0,720 \\
\hline $\mathrm{F}$ & 0,567 & 0,000 & 0,610 & 0,274 & 0,000 & 1,260 & 0,046 & 0,231 & 0,839 & 0,000 & 0,521 & 0,000 & 0,571 & 0,000 & 0,350 & 1,006 \\
\hline $\mathrm{Cl}$ & 0,018 & 0,023 & 0,021 & 0,007 & 0,007 & 0,033 & 0,015 & 0,025 & 0,074 & 0,010 & 0,000 & 0,002 & 0,174 & 0,161 & 0,203 & 0,136 \\
\hline Total & 98,063 & 96,620 & 97,570 & 97,927 & 98,013 & 97,419 & 98,080 & 98,000 & 97,908 & 97,396 & 98,169 & 98,243 & 98,108 & 97,993 & 98,094 & 99,268 \\
\hline \multicolumn{17}{|c|}{ Fórmula estrutural na base de 23 átomos de oxigênio } \\
\hline Si & 6,389 & 6,315 & $6,630^{\circ}$ & 6,864 & 7,280 & 7,140 & 7,014 & 7,158 & 7,079 & 7,325 & 7,438 & 7,508 & 6,586 & 6,715 & 6,963 & 7,235 \\
\hline AlIV & 1,611 & 1,685 & 1,370 & 1,136 & 0,720 & 0,860 & 0,986 & 0,842 & 0,921 & 0,675 & 0,562 & 0,492 & 1,414 & 1,285 & 1,037 & 0,765 \\
\hline $\begin{array}{l}\text { Soma T } \\
\text { Sitios } M 1\end{array}$ & 8,000 & 8,000 & 8,000 & 8,000 & 8,000 & 8,000 & 8,000 & 8,000 & 8,000 & 8,000 & 8,000 & 8,000 & 8,000 & 8,000 & 8,000 & 8,000 \\
\hline \multicolumn{17}{|c|}{ Sitios M1, M2 e M3 } \\
\hline AlVI & 0,192 & 0,147 & 0,201 & 0,218 & 0,136 & 0,085 & 0,134 & 0,209 & 0,143 & 0,100 & 0,125 & 0,113 & 0,137 & 0,149 & 0,097 & 0,092 \\
\hline $\mathrm{Fe} 3+$ & 0,462 & 0,487 & 0,558 & 0,747 & 0,533 & 0,550 & 0,507 & 0,557 & 0,435 & 0,492 & 0,268 & 0,437 & 0,620 & 0,564 & 0,729 & 0,578 \\
\hline $\mathrm{Ti}$ & 0,320 & 0,405 & 0,239 & 0,038 & 0,064 & 0,152 & 0,136 & 0,019 & 0,140 & 0,068 & 0,078 & 0,051 & 0,217 & 0,150 & 0,092 & 0,054 \\
\hline $\mathrm{Mg}$ & 3,057 & 3,100 & 2,912 & 2,449 & 2,947 & 3,073 & 2,828 & 2,647 & 2,969 & 3,274 & 3,342 & 3,335 & 1,356 & 1,316 & 1,675 & 1,792 \\
\hline $\mathrm{Fe} 2+$ & 0,939 & 0,839 & 1,026 & 1,406 & 1,197 & 1,042 & 1,319 & 1,486 & 1,242 & 1,005 & 1,120 & 1,001 & 2,549 & 2,697 & 2,283 & 2,339 \\
\hline $\mathrm{Mn}$ & 0,031 & 0,022 & 0,064 & 0,140 & 0,123 & 0,097 & 0,076 & 0,083 & 0,071 & 0,061 & 0,067 & 0,063 & 0,121 & 0,124 & 0,125 & 0,145 \\
\hline $\begin{array}{l}\text { Soma C } \\
\text { Sitio M4 }\end{array}$ & 5,001 & 5,000 & 5,000 & 4,998 & 5,000 & 4,999 & 5,000 & 5,001 & 5,000 & 5,000 & 5,000 & 5,000 & 5,000 & 5,000 & 5,001 & 5,000 \\
\hline $\mathrm{Ca}$ & 1,816 & 1,772 & 1,797 & 1,853 & 1,823 & 1,707 & 1,821 & 1,866 & 1,831 & 1,790 & 1,837 & 1,809 & 1,759 & 1,779 & 1,739 & 1,760 \\
\hline $\mathrm{Na}$ & 0,184 & 0,228 & 0,203 & 0,147 & 0,177 & 0,293 & 0,179 & 0,134 & 0,169 & 0,210 & 0,163 & 0,162 & 0,241 & 0,221 & 0,261 & 0,240 \\
\hline $\begin{array}{l}\text { Soma B } \\
\text { Sitio A }\end{array}$ & 2,000 & 2,000 & 2,000 & 2,000 & 2,000 & 2,000 & 2,000 & 2,000 & 2,000 & 2,000 & 2,000 & 1,971 & 2,000 & 2,000 & 2,000 & 2,0 \\
\hline $\mathrm{Na}$ & 0,323 & 0,298 & 0,186 & 0,113 & 0,013 & 0,075 & 0,105 & 0,073 & 0,091 & 0,071 & 0,108 & 0,000 & 0,226 & 0,242 & 0,113 & 0,089 \\
\hline K & 0,179 & 0,171 & 0,150 & 0,128 & 0,087 & 0,139 & 0,146 & 0,099 & 0,140 & 0,086 & 0,069 & 0,061 & 0,237 & 0,251 & 0,177 & 0,139 \\
\hline Soma A & 0,502 & 0,469 & 0,336 & 0,241 & 0,100 & 0,214 & 0,251 & 0,172 & 0,231 & 0,157 & 0,177 & 0,061 & 0,463 & 0,493 & 0,290 & 0,228 \\
\hline Soma Cat & 15,503 & 15,469 & 15,336 & 15,239 & 15,100 & 15,213 & 15,251 & 15,173 & 15,231 & 15,157 & 15,177 & 15,032 & 15,463 & 15,493 & 15,291 & 15,228 \\
\hline $\mathrm{Cl}$ & 0,004 & 0,006 & 0,005 & 0,002 & 0,002 & 0,008 & 0,004 & 0,006 & 0,018 & 0,002 & 0,000 & 0,000 & 0,046 & 0,042 & 0,052 & 0,035 \\
\hline $\mathrm{F}$ & 0,261 & 0,000 & 0,283 & 0,128 & 0,000 & 0,585 & 0,021 & 0,107 & 0,388 & 0,000 & 0,236 & 0,000 & 0,280 & 0,000 & 0,169 & 0,480 \\
\hline Al total & 1,80 & 1,83 & 1,57 & 1,35 & 0,86 & 0,95 & 1,12 & 1,05 & 1,06 & 0,78 & 0,69 & 0,61 & 1,55 & 1,43 & 1,13 & 0,86 \\
\hline $\mathrm{Mg} / \mathrm{Mg}+\mathrm{Fe}_{2}$ & 0,77 & 0,79 & 0,74 & 0,64 & 0,71 & 0,75 & 0,68 & 0,64 & 0,71 & 0,77 & 0,75 & 0,77 & 0,35 & 0,33 & 0,42 & 0,43 \\
\hline
\end{tabular}

$\mathrm{BAQMD}=$ biotita-anfibolio-quartzo diorito; $\mathrm{ABMZG}$ a $\mathrm{ABQM}=$ Anfibólio-biotita-monzogr

hornblenda magnesiana; $\mathrm{Tsch}=$ tschermakita; $\mathrm{Act}=$ actinolita: $\mathrm{Fe}-\mathrm{Hb}=$ Ferro-honblenda 
Tabela 2 - Análises de microssonda representativas de biotitas dos granitóides da região de Vila Riozinho.

\begin{tabular}{|c|c|c|c|c|c|c|c|c|c|c|c|c|c|c|c|c|}
\hline \multirow{4}{*}{$\begin{array}{l}\mathrm{n}^{\circ} \text { análise } \\
\text { Mineral }\end{array}$} & \multicolumn{5}{|c|}{ GRANITO SÃO JORGE ANTIGO } & \multirow{3}{*}{\begin{tabular}{|c|} 
GP \\
am $67 \mathrm{c}$ \\
S2P265
\end{tabular}} & \multirow{2}{*}{\multicolumn{2}{|c|}{$\frac{\text { Gr. J. DO OURO }}{\text { ABMZG }}$}} & \multicolumn{8}{|c|}{ GRANITO SÃO JORGE JOVEM } \\
\hline & \multicolumn{2}{|c|}{$\mathrm{ABQM} / \mathrm{ABMZG}$} & \multirow{2}{*}{$\begin{array}{l}\mathrm{ABQS} \\
\mathrm{S} 6 \mathrm{P} 124\end{array}$} & \multicolumn{2}{|c|}{ BLMZG } & & & & \multicolumn{4}{|c|}{ ABMZG-F2/5 } & \multicolumn{2}{|c|}{ ABMZG-F4/29 } & \multicolumn{2}{|c|}{ ABMZG-F9/10 } \\
\hline & S8P129 & S7P84 & & S5P145 & S1P142 & & S8P196 & S8P195 & S3P7 & S3P18 & S2P4 & S2P2 & S1P115 & S3PI14 & S5P72 & S5P71 \\
\hline & Btl & $\mathrm{Btl}$ & $\mathrm{Btl}$ & Bt1 & $\mathrm{Btl}$ & Btl & $\mathrm{Bt1}$ & $\mathrm{Btl}$ & Btl & $\mathrm{Btl}$ & Bt1 & $\mathrm{Bt1}$ & $\mathrm{Bt} 1$ & $\mathrm{Btl}$ & $\mathrm{Btl}$ & Bt1 \\
\hline$\overline{\mathrm{SiO}_{2}}$ & 36,476 & 37,266 & 38,208 & 38,977 & 39,435 & 37,289 & 35,407 & 35,751 & 37,573 & 38,026 & 38,131 & 38,378 & 37,700 & 38,201 & 37,313 & 38,015 \\
\hline $\mathrm{TiO}_{2}$ & 2,199 & 1,866 & 1,851 & 2,111 & 1,659 & 1,818 & 4,551 & 4,391 & 3,005 & 2,483 & 2,645 & 2,644 & 3,158 & 3,143 & 3,566 & 2,670 \\
\hline $\mathrm{Al}_{2} \mathrm{O}_{3}$ & 13,898 & 14,940 & 13,921 & 12,997 & 13,480 & 15,989 & 13,081 & 12,932 & 13,943 & 15,103 & 14,434 & 14,774 & 14,517 & 14,222 & 14,282 & 14,209 \\
\hline $\mathrm{MgO}$ & 12,336 & 12,518 & 12,121 & 13,167 & 13,436 & 9,797 & 6,415 & 6,459 & 13,892 & 13,808 & 14,224 & 13,462 & 13,501 & 13,228 & 12,440 & 13,132 \\
\hline $\mathrm{CaO}$ & 0,049 & 0,022 & 0,021 & 0,070 & 0,000 & 0,004 & 0,028 & 0,094 & 0,006 & 0,000 & 0,000 & 0,000 & 0,019 & 0,040 & 0,000 & 0,029 \\
\hline $\mathrm{MnO}$ & 0,806 & 0,743 & 0,603 & 1,429 & 1,502 & 0,544 & 0,434 & 0,432 & 0,227 & 0,201 & 0,251 & 0,205 & 0,339 & 0,394 & 0,395 & 0,355 \\
\hline $\mathrm{FeO}$ & 18,679 & 18,101 & 18,038 & 15,463 & 14,185 & 21,197 & 27,482 & 27,184 & 17,011 & 15,894 & 15,803 & 15,663 & 16,290 & 16,097 & 16,700 & 15,930 \\
\hline $\mathrm{Na}_{2} \mathrm{O}$ & 0,046 & 0,000 & 0,000 & 0,000 & 0,000 & 0,000 & 0,000 & 0,000 & 0,000 & 0,000 & 0,000 & 0,000 & 0,000 & 0,075 & 0,000 & 0,000 \\
\hline $\mathrm{K}_{2} \mathrm{O}$ & 9,426 & 10,097 & 9,926 & 9,811 & 10,298 & 10,024 & 9,257 & 9,363 & 10,029 & 10,098 & 9,999 & 9,996 & 9,802 & 10,134 & 10,287 & 10,144 \\
\hline $\mathrm{F}$ & 0,404 & 0,223 & 0,758 & 0,461 & 1,376 & 0,348 & 0,465 & 0,213 & 0,571 & 1,232 & 0,765 & 1,004 & 0,724 & 0,291 & 0,410 & 0,905 \\
\hline $\mathrm{Cl}$ & 0,002 & 0,024 & 0,008 & 0,015 & 0,034 & 0,011 & 0,137 & 0,139 & 0,036 & 0,032 & 0,051 & 0,040 & 0,021 & 0,025 & 0,015 & 0,029 \\
\hline TOTAL & 94,321 & 95,800 & 95,454 & 94,501 & 95,405 & 97,020 & 97,258 & 96,957 & 96,292 & 96,876 & 96,302 & 96,164 & 96,071 & 95,849 & 95,407 & 95,419 \\
\hline $\mathrm{O}=\mathrm{F}$ & 0,170 & 0,094 & 0,319 & 0,194 & 0,579 & 0,147 & 0,196 & 0,089 & 0,240 & 0,519 & 0,322 & 0,423 & 0,305 & 0,122 & 0,172 & 0,381 \\
\hline $\mathrm{O}=\mathrm{Cl}$ & 0,000 & 0,005 & 0,002 & 0,003 & 0,008 & 0,003 & 0,031 & 0,031 & 0,008 & 0,007 & 0,011 & 0,009 & 0,005 & 0,006 & 0,003 & 0,007 \\
\hline TOTAL & 94,150 & 95,701 & 95,133 & 94,303 & 94,818 & 96,871 & 97,032 & 96,836 & 96,044 & 96,350 & 95,969 & 95,733 & 95,761 & 95,721 & 95,231 & 95,031 \\
\hline \multicolumn{17}{|c|}{ Fórmula estrutural na base de 22 átomos de oxigênio } \\
\hline $\mathrm{Si}$ & 5,664 & 5,666 & 5,842 & 5,944 & 5,984 & 5,665 & 5,578 & 5,626 & 5,666 & 5,690 & 5,714 & 5,759 & 5,674 & 5,740 & 5,673 & 5,771 \\
\hline AlIV & 2,336 & 2,334 & 2,158 & 2,056 & 2,016 & 2,335 & 2,422 & 2,374 & 2,334 & 2,310 & 2,286 & 2,241 & 2,326 & 2,260 & 2,327 & 2,229 \\
\hline Soma T & 8,000 & 8,000 & 8,000 & 8,000 & 8,000 & 8,000 & 8,000 & 8,000 & 8,000 & 8,000 & 8,000 & 8,000 & 8,000 & 8,000 & 8,000 & 8,000 \\
\hline AIVI & 0,208 & 0,344 & 0,351 & 0,280 & 0,395 & 0,529 & 0,007 & 0,025 & 0,144 & 0,354 & 0,263 & 0,372 & 0,249 & 0,259 & 0,233 & 0,314 \\
\hline $\mathrm{Fe}$ & 2,425 & 2,301 & 2,306 & 1,972 & 1,800 & 2,693 & 3,620 & 3,577 & 2,145 & 1,989 & 1,980 & 1,965 & 2,050 & 2,022 & 2,123 & 2,022 \\
\hline $\mathrm{Mg}$ & 2,863 & 2,845 & 2,770 & 3,001 & 3,047 & 2,224 & 1,510 & 1,519 & 3,131 & 3,088 & 3,185 & 3,019 & 3,037 & 2,970 & 2,827 & 2,980 \\
\hline $\mathrm{Mn}$ & 0,106 & 0,096 & 0,078 & 0,185 & 0,193 & 0,070 & 0,058 & 0,058 & 0,029 & 0,025 & 0,032 & 0,026 & 0,043 & 0,050 & 0,051 & 0,046 \\
\hline $\mathrm{Ti}$ & 0,257 & 0,213 & 0,213 & 0,242 & 0,189 & 0,208 & 0,539 & 0,520 & 0,341 & 0,279 & 0,298 & 0,298 & 0,357 & 0,355 & 0,408 & 0,305 \\
\hline Soma O & 5,859 & 5,799 & 5,719 & 5,680 & 5,624 & 5,724 & 5,734 & 5,699 & 5,789 & 5,735 & 5,758 & 5,680 & 5,737 & 5,657 & 5,642 & 5,666 \\
\hline $\mathrm{Ca}$ & 0,008 & 0,004 & 0,003 & 0,012 & 0,000 & 0,001 & 0,005 & 0,016 & 0,001 & 0,000 & 0,000 & 0,000 & 0,003 & 0,006 & 0,000 & 0,005 \\
\hline $\mathrm{Na}$ & 0,014 & 0,000 & 0,000 & 0,000 & 0,000 & 0,000 & 0,000 & 0,000 & 0,000 & 0,000 & 0,000 & 0,000 & 0,000 & 0,022 & 0,000 & 0,000 \\
\hline $\mathrm{N}$ & 1,867 & 1,958 & 1,936 & 1,908 & 1,993 & 1,943 & 1,860 & 1,880 & 1,929 & 1,927 & 1,911 & 1,913 & 1,882 & 1,942 & 1,995 & 1,964 \\
\hline Soma A & 1,889 & 1,962 & 1,939 & 1,920 & 1,993 & 1,943 & 1,865 & 1,895 & 1,930 & 1,927 & 1,911 & 1,913 & 1,885 & 1,971 & 1,995 & 1,969 \\
\hline $\mathrm{F}$ & 0,198 & 0,107 & 0,366 & 0,222 & 0,660 & 0,167 & 0,231 & 0,106 & 0,272 & 0,583 & 0,362 & 0,476 & 0,345 & 0,138 & 0,197 & 0,434 \\
\hline $\mathrm{Cl}$ & 0,000 & 0,006 & 0,002 & 0,004 & 0,009 & 0,003 & 0,037 & 0,037 & 0,009 . & 0,008 & 0,013 & 0,010 & 0,005 & 0,006 & 0,004 & 0,008 \\
\hline Al total & 2,54 & 2,68 & 2,51 & 2,34 & 2,41 & 2,86 & 2,43 & 2,40 & 2,48 & 2,66 & 2,55 & 2,61 & 2,58 & 2,52 & 2,56 & 2,54 \\
\hline $\mathrm{Mg} / \mathrm{Mg}+\mathrm{Fet}$ & 0,54 & 0,55 & 0,55 & 0,60 & 0,63 & 0,45 & 0,29 & 0,30 & 0,59 & 0,61 & 0,62 & 0,61 & 0,60 & 0,59 & 0,57 & 0,60 \\
\hline
\end{tabular}

$\mathrm{ABQM}=$ Anfibólio-biotita-quartzo-monzonito:

*Dados adicionais de anfibólio e biotita podem ser solicitados ao primeiro autor por correio eletrônico 

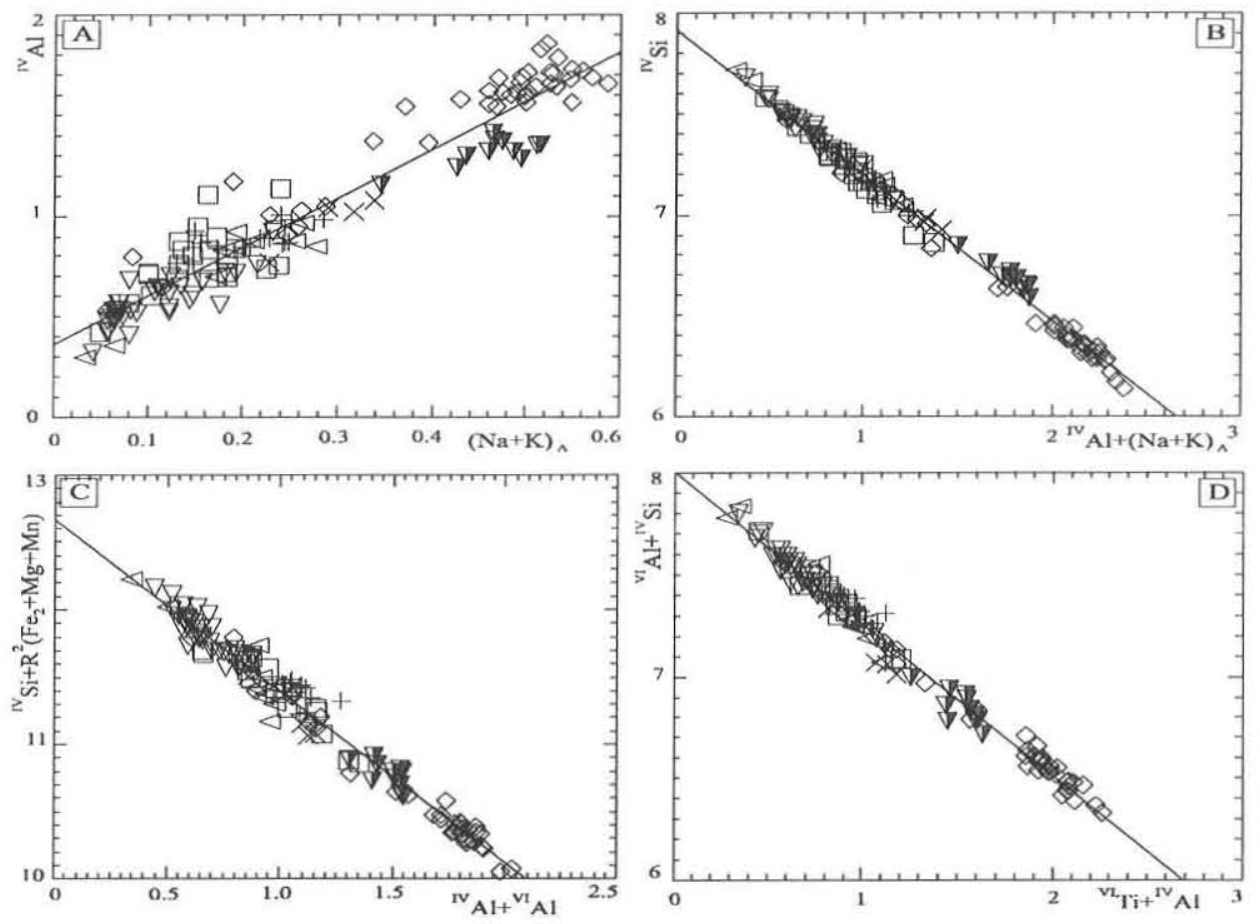

Figura 3 - $(A, B, C, D)$ Diagramas de relações catiônicas de anfibólios dos granitóides da região de Vila Riozinho estudados. Símbolos como na Figura 2.
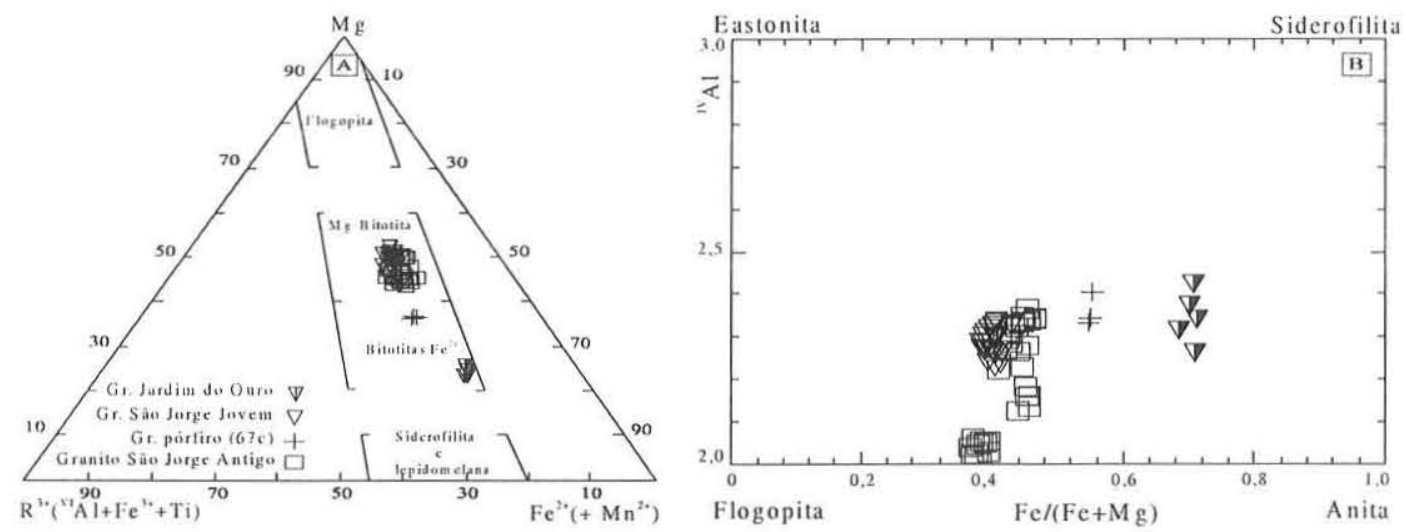

Figura 4 - Diagramas de classificação com a distribuição das biotitas estudadas: (A) Mg- $R^{3+}-F^{2+}$ (Foster 1960), (B) ${ }^{N} \mathrm{Al}-\mathrm{Fe}$ $(\mathrm{Fe}+\mathrm{Mg})($ Deer et al. 1992).

Biotitas de rochas plutônicas são freqüentemente afetadas por reequilíbrio pós-magmático (Speer 1984). No diagrama $\mathrm{TiO}_{2}$ $\mathrm{FeO}+\mathrm{MnO}-\mathrm{MgO}$ (Nachit 1986), as biotitas dos granitos São Jorge Antigo e São Jorge Jovem formam um trend vertical que vai do campo de biotitas primárias para o de biotitas reequilibradas, enquanto as biotitas do Granito Jardim do Ouro plotam no primeiro campo e não mostram evidências de reequilíbrio. As biotitas do granito pórfiro (67c) posicionam-se no domínio de biotitas reequilibradas (Fig. 5A).

COMPOSIÇÃO QUÍMICA DE BIOTITA E TIPOLOGIA DE GRANITÓIDES Vários estudos têm procurado relacionar a composição química das biotitas com a natureza do magma a partir do qual elas cristalizaram. Nachit et al. (1985), utilizando os conteúdos de $\mathrm{Al}_{1}$ e $\mathrm{Mg}$ de biotitas de diferentes granitóides, definiram campos representativos para essas rochas e mostraram a existência de uma relação direta entre a composição química desse mineral e o tipo de magma hospedeiro. Abdel-Rahman (1994) mostrou, por diagramas de elementos maiores das biotitas, que a composição deste mineral é dependente, sobretudo, da natureza do magma original.

No diagrama $\mathrm{Al}_{\mathrm{t}} \times \mathrm{Mg}$ (Fig. 5B), as biotitas dos granitos São Jorge Antigo e São Jorge Jovem distribuem-se nos campos de rochas cálcico-alcalinas e subalcalinas, formando um trend aproximadamente vertical em razão de uma maior variação nos conteúdos de $\mathrm{Al}_{1}$ em relação aos teores pouco variáveis de $\mathrm{Mg}$. A 


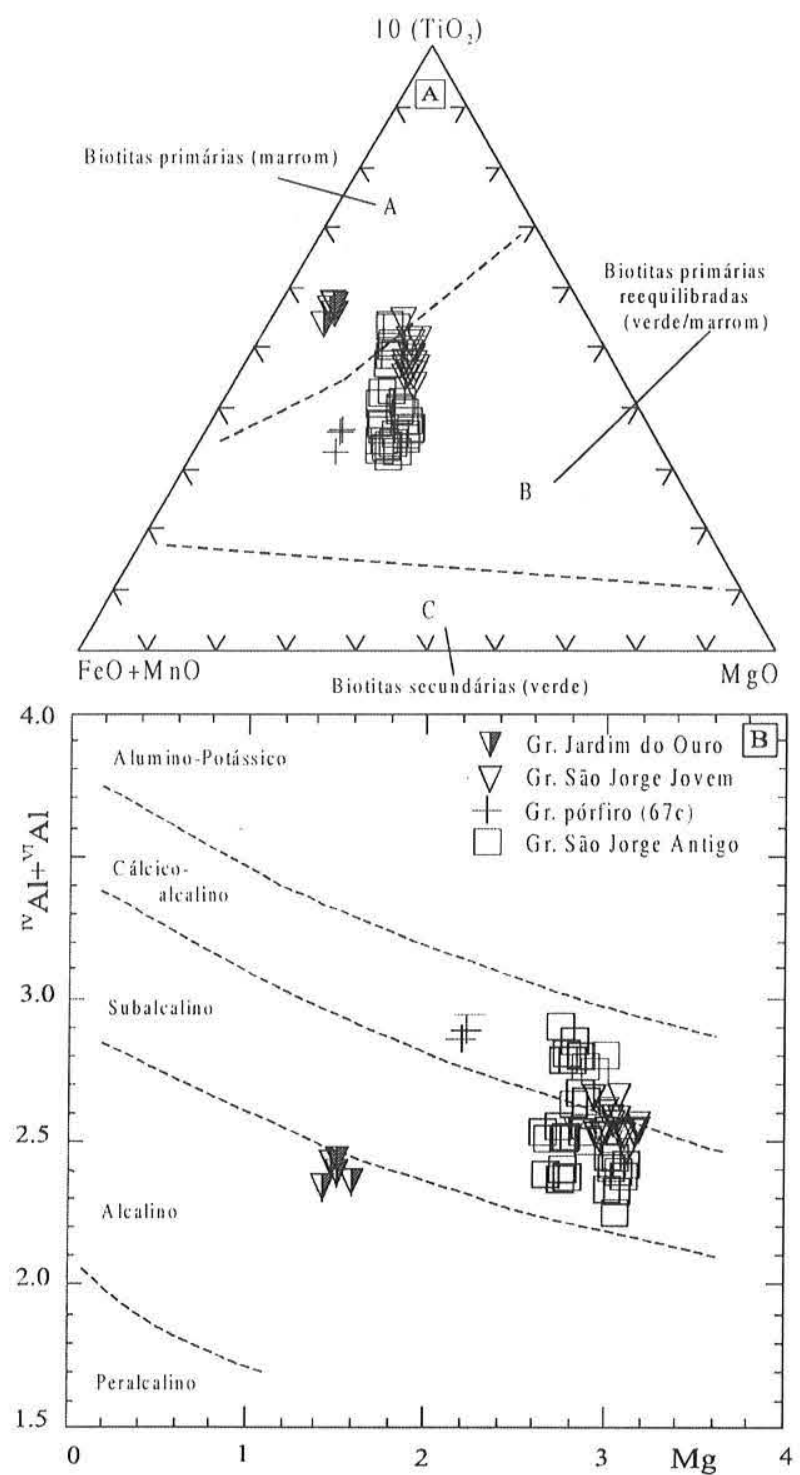

Figura 5 - Diagramas (A) $\mathrm{TiO}_{2}-\mathrm{FeO}+\mathrm{MnO}-\mathrm{MgO}$ (Nachit 1986, óxidos em \% em peso) e (B) Al, x Mg (Nachit et al. 1985) para as biotitas dos granitóides da região de Vila Riozinho.

biotita do granito pórfiro (67c) plota no campo de rochas cálcicoalcalinas, enquanto aquela do Granito Jardim do Ouro posicionase no campo das rochas alcalinas, porém muito próximo do limite com o de rochas subalcalinas.

No diagrama $\mathrm{MgO}-\mathrm{FeO}-\mathrm{Al}_{2} \mathrm{O}_{3}$ (Fig. 6A), as biotitas estudadas plotam igualmente no campo de granitóides cálcico-alcalinos, com exceção da biotita do Granito Jardim do Ouro que mostra um posicionamento mal definido, porém tendendo para o campo de granitos anorogênicos.

Equilíbrio químico entre anfibólios e biotitas A interrelação geoquímica entre anfibólios e biotitas é importante para avaliar o grau de equilíbrio existente entre essas fases minerais. Um dos parâmetros geralmente utilizados para esta avaliação é a razão Fe/ $(\mathrm{Fe}+\mathrm{Mg})$ desses minerais. A Figura $6 \mathrm{~B}$ revela que há boa correspondência entre essas razões nos granitos Jardim do Ouro
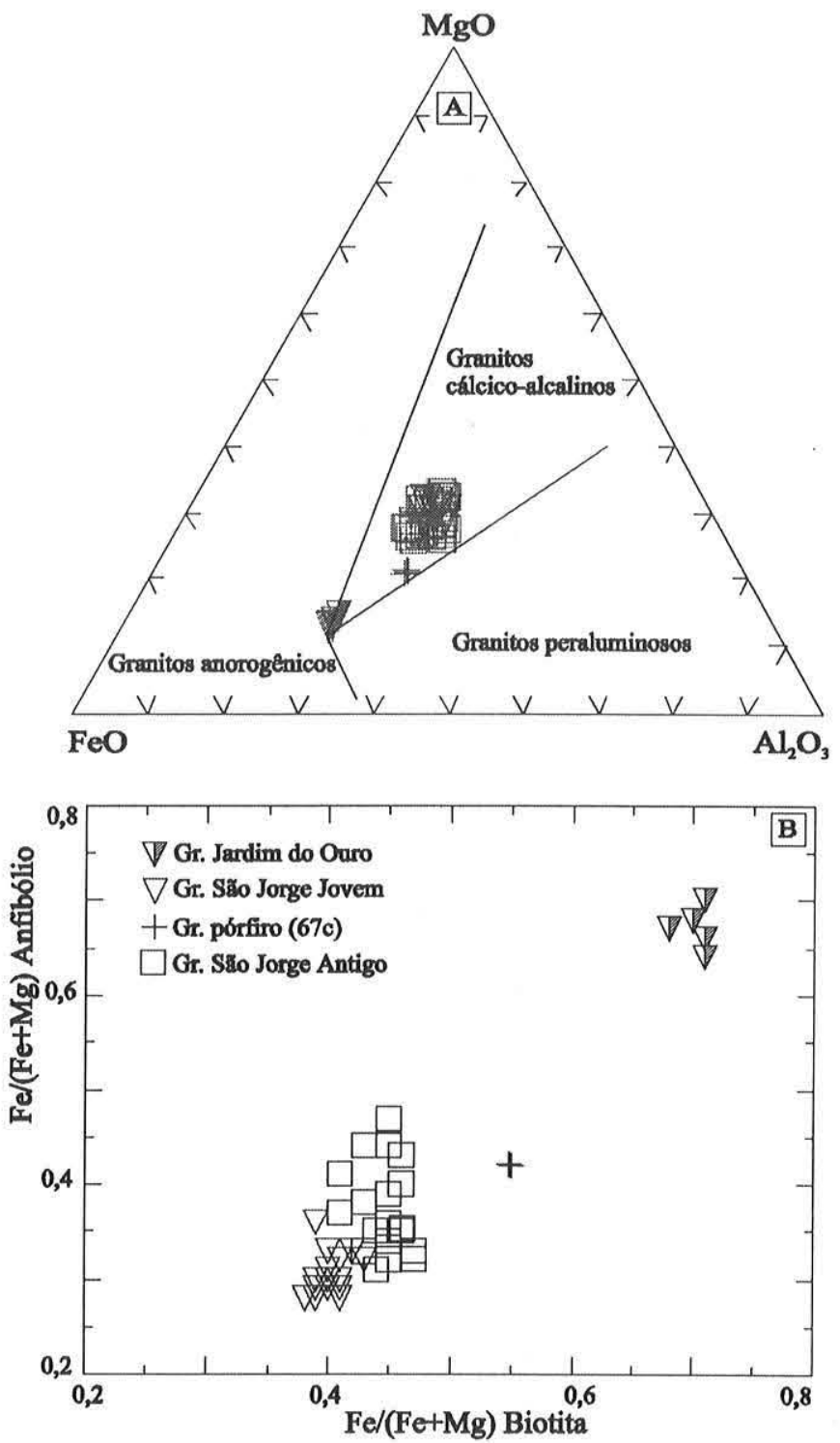

Figura 6 - (A) Diagrama $\mathrm{MgO}-\mathrm{FeO}-\mathrm{Al}_{2} \mathrm{O}_{3}$ (Abdel-Rahman 1994) de classificação de biotitas. (B) Diagrama comparativo entre razões $\mathrm{Fe} /(\mathrm{Fe}+\mathrm{Mg})$ de anfibólios e biotitas de granitóides da região de Vila Riozinho.

e pórfiro (67c) e uma maior variação nos granitos São Jorge Antigo e São Jorge Jovem. Tal comportamento sugere que anfibólios e biotitas cristalizaram em relativo equilíbrio nos dois primeiros corpos, porém sofreram, provavelmente, um reequilíbrio pósmagmático nos dois últimos (cf. Czamanske et al. 1981).

CONDIÇÕESDE CRISTALIZAÇÃO Geobarometria combase no conteúdo de $\mathrm{Al}_{1}$ em anfibólio Na Tabela 3 são apresentadas as pressões de cristalização sugeridas para os granitóides estudados, calculadas com base nos geotermômetros empíricos e experimentais do $\mathrm{Al}$ na hornblenda. Os valores de $\mathrm{Al}_{\text {, }}$ correspondem a análises realizadas apenas nas bordas dos cristais. Os referidos granitóides possuem a paragênese anfibólio-biotita-plagioclásio-álcalifeldspato-quartzo-titanita-magnetita, muito similar àquela 
considerada ideal (Hammarstrom \& Zen 1986; Hollister et al. 1987).

Os geobarômetros empíricos de Harmmarstron \& Zen (1986) e Hollister et al. (1987) e o experimental de Blundy \& Holland (1990) apresentam valores próximos, embora um pouco mais elevados neste último (Tabela 3). Comparando os estudos experimentais de Blundy \& Holland (1990) e Schmidt (1992), o primeiro apoiado, além da pressão, na temperatura como responsável pelas mudanças no $\mathrm{Al}$ dos anfibólios e o segundo essencialmente na pressão, os valores obtidos são ainda mais próximos, sugerindo a influência de variações de temperatura e pressão nessas modificações (conforme Fig. 3A, B, C). O geobarômetro de Johnson \& Rutherford (1989) forneceu pressões dominantemente inferiores às demais, provavelmente em decorrência de sua maior temperatura de calibração, o que proporcionaria um aumento no $\mathrm{Al}_{\mathrm{t}}$ para uma mesma pressão (cf. Anderson \& Smith 1995).

As rochas monzograníticas do Granito São Jorge Antigo teriam cristalizado a pressões que variam entre 3 e 1 kbar e as quartzosieníticas a pressões inferiores a 1,7 kbar (Tabela 3). Valores mais elevados, entre 7 e $5 \mathrm{kbar}$, foram obtidos em Mg-hastingsita e tschermakita de rochas quartzo-monzodioríticas, provavelmente os primeiros anfibólios a cristalizar. Entretanto, a ocorrência de hornblenda-magnesiana nas bordas de muitos cristais de anfibólio dessas rochas sugere um final de colocação e cristalização a pressões próximas daquelas das rochas monzograníticas.

O Granito São Jorge Jovem possui hornblenda magnesiana e actinolita com conteúdos de $\mathrm{Al}_{1}$ comparativamente mais baixos, indicando cristalização a pressões entre 2 e 1 kbar (Tabela 3). Valores em torno de 1 kbar também foram encontrados por Ronchi et al. (2000) a partir do estudo de inclusões fluidas dessas rochas.

O Granito Jardim do Ouro possui anfibólio com conteúdos de $\mathrm{Al}_{1}$ em torno de 1,5 e teria cristalizado a pressões entre 4,6 e 3,0 kbar, inferiores a das rochas monzodioríticas, porém mais elevadas do que aquelas encontradas nas demais fácies do Granito São Jorge Antigo (Tabela 3). Entretanto, como esse anfibólio é mais rico em Fe do que os demais (Fig. 7A) e formou-se em condições menos oxidantes (Fig. 7B), é possível que tal pressão esteja superestimada (cf. Anderson \& Smith 1995).

O granito pórfiro (18a) localizado no contato entre os ignimbritos da Formação Moraes Almeida e as rochas da Suíte Maloquinha (Fig. 1), também possui anfibólio enriquecido em Fe (Fig. 7A). Porém, as pressões sugeridas para o mesmo (2,7 a 1,0 kbar) não destoam muito das dos demais granitóides. Tal fato não implica, porém, que elas não possam estar igualmente exageradas. Sua associação com rochas vulcânicas e subvulcânicas (Fig. 1) aponta neste sentido.

Estimativa de $\mathrm{fo}_{2}$ com base na composição de anfibólios Altas razões $\mathrm{Mg} /(\mathrm{Mg}+\mathrm{Fe})$, tanto em rocha total quanto em minerais ferromagnesianos, são indicativas de cristalização a $\mathrm{fO}_{2}$ elevadas (Frost 1991, Anderson \& Smith 1995), geralmente compatíveis com as condições de formação de granitos da série magnetita (Ishihara 1981). As razões $\mathrm{Mg} /\left(\mathrm{Mg}+\mathrm{Fe}_{2}\right)$ encontradas nos anfibólios dos granitos São Jorge Antigo, São Jorge Jovem e no granito pórfiro associado ao primeiro (amostra 59), sugerem que esses granitóides formaram-se sob condições de $\mathrm{fO}_{2}$ relativamente oxidantes. Essa hipótese é reforçada pelos dados petrográficos que mostram a ocorrência expressiva nessas rochas de titanita e magnetita magmáticas (Figueiredo 1999), considerados minerais indicadores de ambientes oxidantes (Wones 1989). Outras evidências neste sentido são o fato dessas rochas apresentarem sistematicamente valores relativamente elevados de suscetibilidade magnética
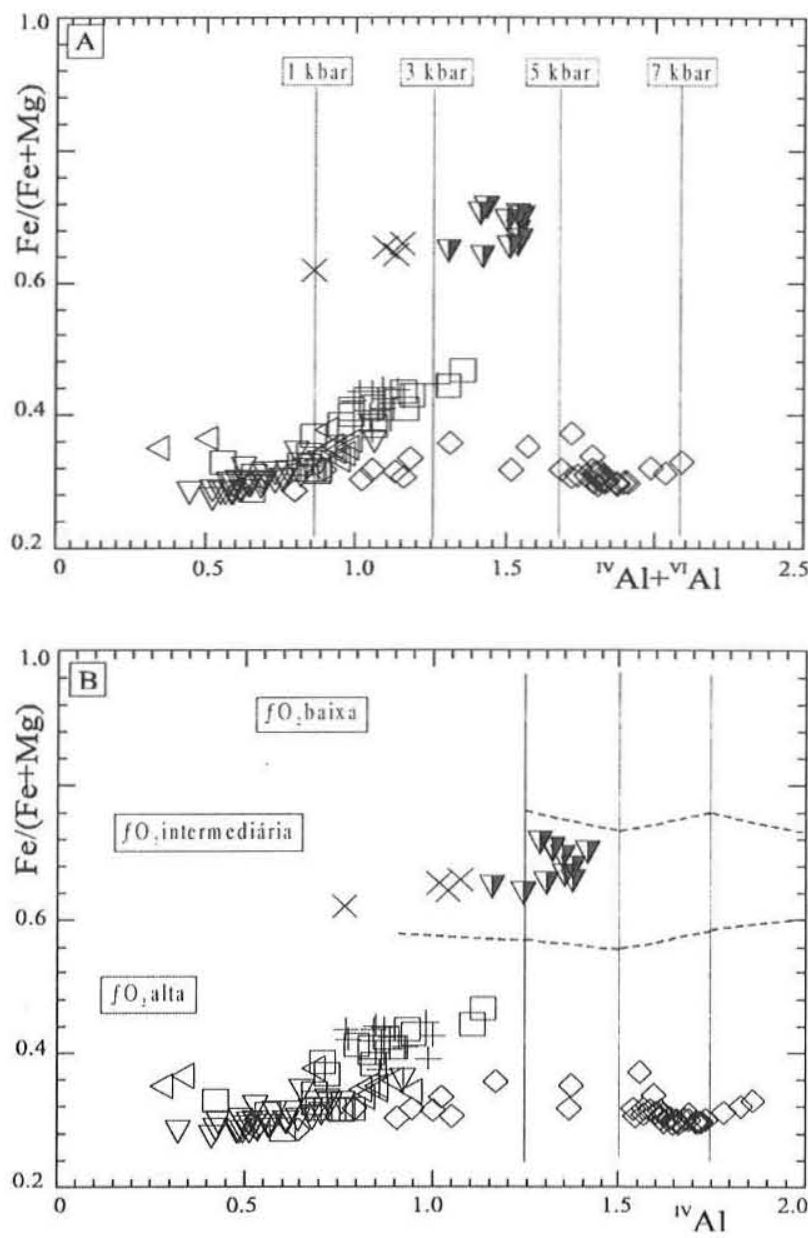

Figura 7 - (A) Diagrama $\mathrm{Fe} /(\mathrm{Fe}+\mathrm{Mg}) \times \mathrm{Al}$, de anfibólios (baseado em Anderson \& Smith 1995) mostrando os possiveis intervalos de pressão de cristalização de anfibólios dos diferentes granitóides estudados; (B) Diagrama $\mathrm{Fe} /(\mathrm{Fe}+\mathrm{Mg}) \mathrm{x}^{\mathrm{IV}} \mathrm{Al}$ de anfibólios (baseado em Anderson \& Smith 1995) mostrando as composições deste mineral nos diferentes granitos estudados $e$ sua provável relação com a $\mathrm{fO}_{2}$ reinante durante sua cristalização. Símbolos como na Figura 2.

(Figueiredo 1999), bem como a composição da biotita (Tabela 2). O Granito Jardim do Ouro e o granito pórfiro 18a possuem anfibólios com razões $\mathrm{Mg} /\left(\mathrm{Mg}+\mathrm{Fe}_{2}\right)$ inferiores e teriam cristalizado num ambiente comparativamente menos oxidante. O diagrama relacionando a razão $\mathrm{Fe} /(\mathrm{Fe}+\mathrm{Mg}) \times{ }^{\mathrm{IV}} \mathrm{Al}$ de anfibólios (Fig. 7B) ilustra de maneira mais clara as relações entre a composição dos anfibólios dos diferentes granitóides e as condições de $f \mathrm{O}_{2}$.

Geotermometria Os intervalos de temperatura (Tabela 4) estimados para os diferentes granitóides foram obtidos com o geotermômetro hornblenda-plagioclásio de Blundy \& Holland (1990) e Holland \& Blundy (1994). São indicadas também para comparação, temperaturas próximas do liquidus para essas rochās (Lamarão 2001) obtidas com o geotermômetro de saturação em Zr (Watson \& Harrison 1983). As temperaturas de saturação em $\mathrm{Zr}$ da fácies BAQMD do Granito São Jorge Antigo não puderam ser determinadas uma vez que as evidências geoquímicas (Lamarão 2001) mostram que a mesma não atingiu saturação nesse elemento. 
Tabela 3 - Pressões de cristalização indicadas para os granitóides da região de Vila Riozinho pelas diferentes formulações do geobarômetro $A l$, em anfibólios.

\begin{tabular}{|c|c|c|c|c|c|c|c|c|}
\hline \multirow[t]{2}{*}{ Granito } & \multirow[t]{2}{*}{ Fácies/Amostra } & \multirow[t]{2}{*}{ Anfibólio } & \multirow[t]{2}{*}{ Al total } & \multicolumn{4}{|c|}{ Pressões (kbar) } & \multirow[b]{2}{*}{ e (\#) } \\
\hline & & & & $\mathrm{a}(*)$ & b (*) & c (\#) & $\mathrm{d}(\#)$ & \\
\hline \multirow{5}{*}{ São Jorge Antigo } & BAQMD & Mg-hast & 2,1 a 1,7 & 6,6 a 4,6 & 7,0 a 4,8 & 5,4 a 3,7 & 7,0 a 5,0 & 7,1 a 5,0 \\
\hline & & Tsch & 1,9 a 1,7 & 5,6 a 4,6 & 5,9 a 4,8 & 4,6 a 3,7 & 6,0 a 5,0 & 6,0 a 5,0 \\
\hline & & $\mathrm{HbMg}$ & 1,6 a 1,0 & 4,1 a 1,1 & 4,3 a 0,9 & 3,3 a 0,8 & 4,5 a 1,5 & 4,6 a 1,7 \\
\hline & ABMZG a $A B Q M$ & $\mathrm{HbMg}$ & 1,3 a 0,85 & 2,6 a 0,9 & 2,6 a 0,6 & 2,0 a 0,6 & 3,0 a 1,2 & 3,2 a 1,5 \\
\hline & $\mathrm{ABQS}$ & $\mathrm{HbMg}$ & 1,0 a 0,9 & 1,1 a 0,7 & 0,9 a 0,5 & 0,8 a 0,4 & 1,5 a 1,0 & 1,7 a 1,3 \\
\hline São Jorge Jovem & $\mathrm{ABMZG}$ & $\mathrm{HbMg}$ & 1,1 a 0,9 & 1,6 a 0,6 & 1,4 a 0,3 & 1,2 a 0,4 & 2,0 a 1,0 & 2,3 a 1,3 \\
\hline \multirow[t]{2}{*}{ Jardim do Ouro } & ABMZG & Fe-hb & 1,6 a 1,3 & 4,1 a 2,6 & 4,3 a 2,6 & 3,3 a 2,0 & 4,5 a 3,0 & 4,6 a 3,2 \\
\hline & & Fe-ed & 1,5 & 3,6 & 3,7 & 2,9 & 4,0 & 4,1 \\
\hline Pórfiro & 59 & $\mathrm{HbMg}$ & 1,1 a 1,0 & 2,6 a 1,1 & 2,3 a 0,9 & 2,0 a 0,8 & 3,0 a 1,5 & 3,2 a 1,7 \\
\hline Pórfiro & $18 \mathrm{a}$ & $\mathrm{Fe}-\mathrm{hb}$ & 1,2 a 0,9 & 2,1 a 0,6 & 2,0 a 0,3 & 1,6 a 0,4 & 2,5 a 1,0 & 2,7 a 1,3 \\
\hline $\begin{array}{l}\text { - Harmmarstron } \\
\text { Rutherford ( } 19 \\
\text { ( } \pm 0,6 \text { kbar) } \\
\text { nfibólio-biotita- }\end{array}$ & -sienito; $A B M$ & Anfibe & $-3,92 ; b-$ & lister et al. & 1987): $P( \pm$ & $\begin{array}{l}(\text { kbar })= \\
5,03 \text { Alt } \\
\text { ólio-quar }\end{array}$ & 4 Alt $-4,76$ & $\begin{array}{l}c-\text { Johnson } \\
\text { nidt (1992): } \\
\text { o: } A B Q S= \\
\text { kita; } \mathrm{HbMg}\end{array}$ \\
\hline
\end{tabular}

Tabela 4 - Temperaturas de cristalização estimadas para os granitóides da região de Vila Riozinho com base nos geotermômetros hornblenda-plagioclásio e saturação em $\mathrm{Zr}$.

\begin{tabular}{cccccc}
\hline Granito & Fácies/Amostra & Anfibólio & $\mathrm{THb}-\mathrm{Pl}\left({ }^{\circ} \mathrm{C}\right)$ & $\mathrm{THb}-\mathrm{Pl}\left({ }^{\circ} \mathrm{C}\right)$ & $\mathrm{TZr}\left({ }^{\circ} \mathrm{C}\right)$ \\
\hline & & & 1 & 2 & 3 \\
\hline \multirow{3}{*}{ São Jorge Antigo } & BAMQMD & Mg-hast & $893-787$ & $901-843$ & $\mathrm{x}$ \\
& $\mathrm{ABQS}$ & $\mathrm{HbMg}$ & $736-630$ & $726-671$ & $844-825$ \\
\hline São Jorge Jovem & $\mathrm{ABMZG}$ & $\mathrm{HbMg}$ & $677-537$ & $686-654$ & $796-770$ \\
\hline Jardimdo Ouro & $\mathrm{ABMZG}$ & $\mathrm{Fe}-\mathrm{Hb}$ & $803-686$ & $775-736$ & 795 \\
\hline Pórfiro & 59 & $\mathrm{HbMg}$ & $\mathrm{x}$ & $\mathrm{x}$ & $814-808$ \\
Pórfiro & $18 \mathrm{a}$ & $\mathrm{Fe}-\mathrm{Hb}$ & $772-685$ & $810-713$ & 876 \\
\hline
\end{tabular}

$I=$ Blundy \& Holland (1990); 2 = Holland \& Blundy (1994); 3 = Watson \& Harrison (1983). BAQMD = Biotita-anfibólio-quartzo-monzodiorito; $A B Q S=$ Anfibólio-biotita-quartzo-sienito; $A B M Z G=$ Anfibólio-biotitamonzogranito; $M g$-has $t=M g$-hastingsita; $H b M g=H o r n b l e n d a$ magnesiana: $F e-h b=$ Ferro-hornblenda.

Os BAQMD do granito São Jorge Antigo indicaram temperaturas entre $900-840^{\circ} \mathrm{C}$ com o geotermômetro de Holland \& Blundy (1994). Os ABMZG+ABQM deste granito e os ABMZG do Granito São Jorge Jovem forneceram temperaturas entre 685$553{ }^{\circ} \mathrm{C}$ e $686-654{ }^{\circ} \mathrm{C}$, respectivamente. Tais temperaturas são comparativamente inferiores àquelas obtidas com o geotermômetro de saturação em $\mathrm{Zr}$ (Tabela 4). Essas diferenças poderiam estar relacionadas a um reequilíbrio sofrido pelos anfibólios desses dois últimos granitos e, neste caso, as temperaturas obtidas não seriam representativas das reinantes durante a cristalização magmática. Para o granito Jardim do Ouro, as temperaturas obtidas com o geotermômetro de Holland \& Blundy (1994) situam-se entre $775-736^{\circ} \mathrm{C}$, próximas da temperarura de saturação em $\mathrm{Zr}\left(795^{\circ} \mathrm{C}\right)$. O granito pórfiro 18a apresentou temperaturas entre 810 e $713^{\circ} \mathrm{C}$ com o geotermômetro hornblendaplagioclásio e de $876^{\circ} \mathrm{C}$ com o geotermômetro de saturação em $\mathrm{Zr}$.

As temperaturas obtidas com o geotermômetro de Blundy \&
Holland (1990), por outro lado, apresentaram diversos valores abaixo da temperatura do solidus admitida para sistemas graníticos afins (em torno de $700^{\circ} \mathrm{C}$, Naney 1983, Johannes \& Holtz 1996).

Dentre as temperaturas obtidas, as indicadas pelo geotermômetro do zircão são muito provavelmente as mais representativas das reinantes em condições próximas do liquidus nas diferentes fácies. Este geotermômetro tem-se mostrado coerente com dados experimentais, como no caso do granito Jamon (Dall'Agnol et al. 1999b).

CONSIDERAÇÕES E CONCLUSÕES Os dados de química mineral de anfibólios e biotitas revelaram diferenças e semelhanças significativas entre os vários granitóides da região de Vila Riozinho. $\mathrm{O}$ anfibólio do granito São Jorge Antigo varia de Mg-hastingsita e tschermakita a hornblenda magnesiana, e no granito São Jorge Jovem de hornblenda magnesiana a actinolita, todos com razões $\mathrm{Mg} /\left(\mathrm{Mg}+\mathrm{Fe}_{2}\right)$ elevadas, sugerindo formação em condições oxidantes. No Granito Jardim do Ouro, predomina Fe-hornblenda e, raramente Fe-edenita, com razões $\mathrm{Mg} /\left(\mathrm{Mg}+\mathrm{Fe}_{2}\right)$ inferiores e formadas, ao que tudo indica, num ambiente comparativamente menos oxidante.

Os dois granitos pórfiros estudados possuem anfibólios composicionalmente distintos. No primeiro, associado ao Granito São Jorge Antigo (amostra 59), predomina hornblenda magnesiana de composição similar à do anfibólio das fácies ABMZG+ABQM, sugerindo uma ligação genética e temporal entre essas rochas. Os dados geoquímicos (Lamarão 2001, Lamarão et al. 2002, Lamarão \& Dall'Agnol 2002) também apontam neste sentido. No segundo (amostra 18a), associado aos ignimbritos e às rochas da Suíte Maloquinha, ocorrem Fe-hornblendas similares às observadas do Granito Jardim do Ouro, sugerindo uma ligação daquele pórfiro com este corpo granítico. Tais dados reforçam a existência de pelo menos duas gerações distintas de granitos pórfiros na região.

As biotitas dos granitos São Jorge Antigo, São Jorge Jovem e pórfiro (67c), são ricas em Mg, distribuem-se no campo de granitos cálcio-alcalinos a subalcalinos e mostram características de biotitas reequilibradas. As biotitas do Granito Jardim do Ouro, por outro lado, são mais ricas em Fe deslocando-se em direção ao polo da anita, tendem para o campo de granitos alcalinos e não apresentam sinais de reequilíbrio. 
Pressões entre 3 e 1 kbar e inferiores a 1,7 kbar foram obtidas, respectivamente, para monzogranitos e quartzo-sienitos do Granito São Jorge Antigo pelo geobarômetro do $\mathrm{Al}$ na hornblenda. Pressões mais elevadas $(6 \pm 1 \mathrm{kbar})$ foram registradas em $\mathrm{Mg}$ hastingsita e tschermakita de monzodioritos deste corpo. Entretanto, a ocorrência de hornblenda magnesiana nas bordas de diversos cristais de anfibólio dessas rochas sugere um final de colocação e cristalização a pressões similares àquelas das rochas monzograníticas. O granito pórfiro associado ao Granito São Jorge Antigo (amostra 59), possui anfibólio com conteúdos de $\mathrm{Al}_{\text {, que }}$ se superpõem ao dos $A B M Z G+A B Q M$ deste corpo, sugerindo níveis similares de colocação e reforçando a hipótese de uma provável ligação genética entre ambos. O Granito São Jorge Jovem, com base na composição de hornblenda magnesiana, formou-se a pressões entre 2 e 1 kbar. Entretanto, a ocorrência considerável neste granito de anfibólio com composição actinolítica sugere a possibilidade de reequilíbrio subsolidus e tais valores devem ser tomados com cautela. O Granito Jardim do Ouro e o granito pórfiro associado aos ignimbritos e às rochas da Suíte Maloquinha (amostra 18a), teriam cristalizado a pressões de 4,5 a 3,0 kbar e 2,7 a 1,0 kbar, respectivamente. Porém, como os anfibólios desses granitos são muito mais ricos em Fe do que os demais e formaramse em $f \mathrm{O}$, mais baixa, é possível que seus conteúdos de $\mathrm{Al}$ tenham sido afetados, acarretando um aumento aparente da pressão.
O geotermômetro de Holland \& Blundy (1994) indicou temperaturas entre $900-840^{\circ} \mathrm{C}$ para as rochas quartzomonzodioríticas do Granito São Jorge Antigo. Para as rochas monzograníticas e quartzo-sieníticas deste corpo e as monzograníticas do Granito São Jorge Jovem as temperaturas registradas foram de 685 a $553^{\circ} \mathrm{Ce} 686$ a $654^{\circ} \mathrm{C}$, respectivamente. Essas temperaturas são comparativamente bem inferiores àquelas obtidas com o geotermômetro de saturação em $\mathrm{Zr}$ e podem estar refletindo um provável reequilíbrio sofrido pelos anfibólios desses dois últimos granitos. Para o granito Jardim do Ouro, as temperaturas obtidas com o mesmo geotermômetro situam-se entre 775 e $736^{\circ} \mathrm{C}$, próximas da temperarura de saturação em $\mathrm{Zr}\left(795^{\circ} \mathrm{C}\right)$. $\mathrm{O}$ granito pórfiro (18a), por outro lado, apresentou temperaturas entre $810 \mathrm{e} 713^{\circ} \mathrm{C}$ com o geotermômetro hornblenda-plagioclásio e de $876^{\circ} \mathrm{C}$ com o de saturação em $\mathrm{Zr}$. As temperaturas de saturação em $\mathrm{Zr}$ são provavelmente indicativas daquelas próximas do liquidus para as diferentes fácies e corpos graníticos.

Agradecimentos Os autores agradecem a empresa Rio Tinto Desenvolvimento Minerais-RTDM, a ADIMB, ao Instituto de Geociências da UFRGS, ao Centro de Geociências da UFPA, ao $\mathrm{CNPq}$ e a Capes. Este trabalho é uma contribuição aos projetos PRONEX/CNPq (Proj. 103-98 - Proc. 66.2103/1998-0) e IGCP-426. Aos revisores da RBG pelas sugestões ao manuscrito.

\section{Referências}

Abdel-Rahman A.M. 1994. Nature of biotites from alkaline, calc-alkaline, and peraluminous magmas. J. Petrol., 35:525-541.

Almeida M.E., Brito M.F.L., Ferreira A.L., Monteiro M.A.S. 2000. Projeto especial Província Mineral do Tapajós. Geologia e Recursos Minerais da Folha Mamãe Anã (SB-2I-V-D). Estados do Pará e Amazonas. Escala 1:250.000. CPRM. (Nota explicativa, em CDROM).

Anderson J.L. \& Smith, D.R. 1995. The effects of temperature and $\mathrm{fO}_{2}$ on the $\mathrm{Al}$-in-hornblende barometer. Am. Mineral., 80:549-559.

Bahia R.B.C. \& Quadros M.L.E.S. 2000. Geologia e recursos minerais da Folha Caracol (SB-21-X-C), Estado do Pará. Escala 1:250.000. CPRM. (Nota explicativa, em CD-ROM).

Blundy J.D. \& Holland T.J.B. 1990. Calcic amphibole equilibria and a new amphibole-plagioclase geothermometer. Contr: Mineral. Petrol., 104:208-224.

Brito M.F., Almeida L.M.E., Macambira M.J.B. 1999. ${ }^{207} \mathrm{~Pb} /{ }^{200} \mathrm{~Pb}$ age of Calc-Alkaline Rapakivi Granite in Tapajós Gold Province, Amazon Craton-Brazil. In: South American Symposium on Isotope Geology, 2nd. Expanded abstract, p. 40-43.

Chivas A.R. 1981. Geochemical Evidence for Magmatic Fluids in Porphyry Copper Mineralization. Part I. Mafic Silicates from Koloula Igneous Complex. Contrib. Mineral. Petrol., 78:389-403.

Czamanske G.K. \& Wones D.R. 1973. Oxidation During Magmatic Differentiation, Finnmarka Complex, Oslo Area, Norway: Part 2: The Mafic Silicates. J. Petrol. 14:348-380.

Czamanske G.K., Ishihara S., Atkin S.A. 1981. Chemistry of rock-forming minerals of the Cretaceous-Paleocene batholith in Southwestern
Japan and implications for magma genesis. J. Geophys. Res. 86: $10431-10469$

Dall'Agnol R. \& Silva C.M. G. 1991. Os Riolitos com faialita e clinopiroxênio da região do Baixo Rio Jamanxim: dados preliminares. In: SBG, Simp. Geol. Amazônia, 3. Belém. Anais, p. 603.

Dall'Agnol R., Silva C.M.G., Scheller T. 1999a. Fayalite-hedembergite rhyolites of the Iriri Formation, Tapajós Gold Province, Amazonian Craton: Implications for the Uatumã volcanism. In: Simp. sobre Vulcanismo e Ambientes Associados, 1, Gramado, Boletim de resumos, p. 31 .

Dall'Agnol R., Scaillet B., Pichavant M. 1999b. An experimental study of a Lower Proterozoic A-type granite from the Eastern Amazonian Craton, Brazil. J. Petrol., 40:1673-1698.

Deer W.A., Howie R.A., Zussman J. 1992. Rock-forming minerals. London, 2" Ed. Longmans (eds.), 696 p.

Dymek R.F. 1983. Titanium, aluminium and interlayer cation substitutions in biotite from high-grade gnaisses, West Greenland. Am. Mineral., 68:880-899.

Faraco M.T.L., Carvalho J.M.A., Klein E.L. 1997. Carta Metalogenética da Província Aurífera do Tapajós. In: M.L. Costa \& R.S. Angélica (eds). Contribuiçôes à Geologia da Amazônia. Belém, FINEP, SBGNO, p. 423-437.

Figueiredo M.A.B.M. 1999. Minerais óxidos de Fe e Tie Suscetibilidade Magnética em vulcânicas e granitóides Proterozóicos de Vila Riozinho, Província Aurífera do Tapajós. Dissertação de Mestrado, Centro de Geociências, Universidade Federal do Pará, 171p.

Foster M.D. 1960. Interpretation of the composition of trioctahedral micas. U. S. Geol. Surv., Prof. Paper, 354:1-49. 
Frost R.B. 1991. Introduction to oxigen fugacity and its petrologic importance. In: Lindsley, D. H. (ed.). Oxide minerals: petrologic and magnetic significance, pp.: 1-9.

Hammarstron J.M. \& Zen E.A. 1986. Aluminium in hornblende: an empirical igneous geobarometer. Am. Mineral., 71:1297-1313.

Holland T.J.B. \& Blundy J.D. 1994. Non-ideal interactions in calcic amphiboles and their bearing on amphibole-plagioclase thermometry. Contrib. Mineral. Petrol., 116:433-447

Hollister L.S., Grisson G.C., Peters E.K., Stowell H.H., Sisson V.B. 1987. Confirmation of the empirical correlation of $\mathrm{Al}$ in hornblende with pressure of solidification of calc-alkaline plutons. Am. Mineral., 72:231-239.

Ishihara S. 1981. The granitoid series and mineralization. Econ. Geol., 75:458-484

Johnson M.C. \& Rutherford M.J. 1989. Experimental calibration of the aluminium-in-hornblende geobarometer with application to Long Valley caldera (California) volcanic rocks. Geology, 17:837-841.

Johannes W. \& Holtz F. 1996. Petrogenesis and Experimental Petrology of Granitic Rocks. Springer, Berlim, 335 pp.

Klein E.L. \& Vasquez M.L. 2000. Projeto especial Província Mineral do Tapajós. Geologia e recursos minerais da Folha Vila Riozinho(SB.21Z-A). Estado do Pará. Escala 1:250.000. CPRM. (Nota explicativa, em CD-Rom).

Lamarão C.N., Dall'Agnol R., Lafon J.M., Lima E. F. 1999. Associações vulcânicas e plutônicas de Vila Riozinho e Moraes Almeida, Província Aurífera do Tapajós, SW do Estado do Pará. In: Simp. sobre Vulcanismo e Ambientes Associados, 1, Gramado, Boletim de resumos, p. 93.

Lamarão C.N. 2001. Geologia, Geoquímica e Geocronologia do Magmatismo Paleoproterozóico da Região de Vila Riozinho, Província Aurífera do Tapajós, Cráton Amazônico. Tese de Doutoramento, Centro de Geociências, Universidade Federal do Pará., 285 p.

Lamarão C.N. \& Dall'Agnol R. 2002. Granitóides São Jorge Antigo e São Jorge Jovem: petrografia e geoquímica de magmatismo cálcico-alcalino alto-K paleoproterozóico na Província Aurífera do Tapajós, Cráton Amazônico. In: Klein, E.L., Vasquez M.L. \& Rosa-Costa L.T. (Eds.) Contribuições à Geologia da Amazônia. SBG-NO, Belém, vol. 3, p. $53-66$.

Lamarão C.N., Dall' Agnol R., Lafon J-M., Lima E.F. 2002. Geology, Geochemistry and $\mathrm{Pb}-\mathrm{Pb}$ zircon Geochronology of the Paleoproterozoic Magmatism of Vila Riozinho, Tapajós Gold Province, Amazonian Craton, Brazil. Prec. Res. 119:189-223

Leake B.E., Wooley A.R., Arps C.E.S., Birch W.D., Gilbert M.C., Grice J.D., Hawthorne F.C., Kato A., Kisch H.J., Krivovichev V.G., Linthout K., Laird J., Mandarino J.A., Maresch W.V., Nickel E.H. Schumacher J., Smith J.C., Stephenson N.C. N., Ungaretti L., Whittaker E.J.W., Youzhi G. 1997. Nomenclature of Amphiboles: Report of the Subcommittee on Amphiboles of the International Mineralogical Association Commission on New Minerals and Mineral Names. Mineral. Mag., 61:295-321.

Moura C.A.V., Gorayeb P.S.S., Matsuda N.S. 1999. Geocronologia PbPb em zircão do Riolito Vila Raiol, Formação Iriri-sudoeste do Pará. In: SBG, Simp. Geol. Amazônia, 6, Manaus. Boletim de resumos expandidos, p. 475-477.
Nachit H., Razafimahefa N., Stussi J.M., Carron J.P. 1985. Composition chimique des biotites et typologie magmatique des granitoides. C. $R$. Acad. Sci. Paris, 301:813-818.

Nachit H. 1986. Contribution à l'étude analytique et expérimentale des biotites des granitoïdes. Applications typologiques, Tese de doutoramento, Université de Bretagne Occidentale, 181 pg.

Naney M.T. 1983. Phase equilibria of rock-forming ferromagnesian silicates in granitic systems. Am. Jour: Sci., 283:993-1033.

Quadros M.L.E.S., Bahia R.B.C., Klein E.L., Vasquez M.L., Almeida M.E., Ricci P.S.F., Monteiro M. A.S. 1999. As intrusões básicas da Província Mineral do Tapajós (PMT) e possibilidades de mineralizações associadas. In: SBG, Simp. Geol. Amazônia, 6, Manaus. Boletim de resumo expandidos, p. 566-569.

Ricci P.S.F., Vasquez M.L., Santos A., Klein E.L., Jorge João X.S., Martins R.C. 1999. Suíte Intrusiva Creporizão-Província Tapajós: proposta e critérios de definição. In: SBG, Simp. Geol. Amazônia, 6, Manaus. Boletim de resumos expandidos, p. 519-522.

Richard L.R. 1995. Minpet Software. Mineralogical and Petrological data processing system. Versão 2.02. Copyright (1988-1995).

Ronchi L.R., Dall'Agnol R., Lamarão C.N., Borges R.M.K. 2000. Fluid inclusions in the gold deposit of the São Jorge Granite, Tapajós, Brazil. In: Intern. Geol. Congr., 31st, Rio de Janeiro. Abstracts volume. (in $\mathrm{CD}-\mathrm{ROM}$ ).

Santos J.O.S. 1984. Classificação das rochas vulcânicas Uatumã. In: SBG, Congr. Bras. Geol., 33, Rio de Janeiro. Anais, p. 4535-4538

Santos D.B, Fernandes P.E., Dreher A.M., Cunha F.M.B., Basei M.A.S. Teixeira J.B.G. 1975. Geologia da Folha SB-21-Tapajós - Projeto RADAM. DNPM. Rio de Janeiro. Levantamento dos Recursos Naturais. v.7, p. 15-116.

Santos J.O.S., Hartmann L.A., Gaudette H.E., Groves D.I., Mcnaughton N.J., Fletcher I.R. 2000. A new understanding of the Provinces of the Amazon Craton based on integration of field and U-Pb and SmNd geochronology. Gond. Res., 3:453-488.

Santos J.O.S., Hartmann L.A., McNaughton N.J., Fletcher I.R. 2001. Timing of mafic magmatism in the Tapajós Province (Brazil) and implications for the evolution of the Amazon Craton: evidence from baddeleyite and zircon U-Pb SHRIMP geochronology. J. South Am. Earth Sci. 15:409-429.

Schmidt M.W. 1992. Anphibole composition in tonalites as a function of pressure: an experimental calibration of the $\mathrm{Al}$-in-hornblende barometer. Contrib. Mineral. Petrol., 110:304-310.

Speer J.A. 1984. Micas in igneous rocks. In: Bailey, S. W. (ed.), Micas. Reviews in Mineralogy, 13, pp.: 299-356.

Tassinari C.C.G. \& Macambira M.J.B. 1999. Geochronological Provinces of the Amazonian Craton. Episodes, 22:174-182.

Vasquez M.L., Klein E.L., Quadros M.L.E., Bahia R.B.C., Santos A., Ricci P., Sachett C.R., Silva C. M.G., Macambira M.J.B. 1999. Magmatismo Uatumã na Província Tapajós - Novos dados geocronológicos. In: SBG, Simp. Geol. Amazônia, 6, Manaus. Boletim de resumos expandidos, p. 471-474.

Vasquez M.L., Klein E.L., Macambira M.J.B., Santos A., Bahia R.B.C., Ricci P.S.F., Quadros M.L.E. 2000. Geochronology of granitoids, mafic intrusions and mineralizations of the Tapajós Gold Province- 
Quimica mineral de anfibólios e biotitas e condiçôes de cristalização de granitóides paleoproterozóicos da regiāo de Vila Riozinho, Província Aurifera do Tapajós, Cráton Amazônico

Amazonian Craton-Brazil. In: International Geological Congress, 31. Abstracts volume. (in CD-ROM).

Vasquez M.L., Klein E.L., Ricci P.S.F. 2001. Granitóides pós-colisionais da porção leste da Província Tapajós. In: SBG, Simp. Geol. Amazônia, 7. Belém. (em CD-ROM).

Vyhnal C.R., McSween Jr. H.Y., Speer J.A. 1991. Hornblende chemistry in southern Appalachian granitoids: Implications for aluminum hornblende thermobarometry and magmatic epidote stability. Am. Mineral., 76:176-188.
Watson E.B. \& Harrison T.M. 1983. Zircon saturation revisited: temperature and composition effects in a variety of crustal magma types. Earth Planet. Sci. Lett., 64:295-304.

Wones D.R. 1989. Significance of the assemblage titanite + magnetite + quartz in granitic rocks. Am. Mineral., 74:744-749.

Manuscrito A-1410

Recebido em 19 de fevereiro de 2003

Revisão dos autores em 25 de novembro de 2003

Revisão aceita em 02 de dezembro de 2003 